\title{
1 Evaluating Simplifications of Subsurface Process \\ 2 Representations for Field-scale Permafrost Hydrology Models
}

3 Bo Gao, Ethan T. Coon

4 Environmental Sciences Division, Oak Ridge National Laboratory, Oak Ridge, Tennessee, USA

5 Correspondence to: Ethan T. Coon (coonet@ornl.gov)

6 Abstract. Permafrost degradation within a warming climate poses a significant environmental

7 threat through both the permafrost carbon feedback and damage to human communities and

8 infrastructure. Understanding this threat relies on better understanding and numerical

9 representation of thermo-hydrological permafrost processes, and the subsequent accurate

10 prediction of permafrost dynamics. All models include simplified assumptions, implying a tradeoff

11 between model complexity and prediction accuracy. The main purpose of this work is to

12 investigate this tradeoff when applying the following commonly made assumptions: (1) assuming

13 equal density of ice and liquid water in frozen soil; (2) neglecting the effect of cryosuction in

14 unsaturated freezing soil; and (3) neglecting advective heat transport during soil freezing and thaw.

15 This study designed a set of 62 numerical experiments using the Advanced Terrestrial Simulator

16 (ATS v1.2) to evaluate the effects of these choices on permafrost hydrological outputs, including

17 both integrated and pointwise quantities. Simulations were conducted under different climate

18 conditions and soil properties from three different sites in both column- and hillslope-scale

19 configurations. Results showed that amongst the three physical assumptions, soil cryosuction is

20 the most crucial yet commonly ignored process. Neglecting cryosuction, on average, can cause $10 \%$

$21 \sim 20 \%$ error in predicting evaporation, $50 \% \sim 60 \%$ error in discharge, $10 \% \sim 30 \%$ error in thaw

22 depth, and $10 \% \sim 30 \%$ error in soil temperature at $1 \mathrm{~m}$ beneath surface. The prediction error for

23 subsurface temperature and water saturation is more obvious at hillslope scales due to the presence

24 of lateral flux. By comparison, using equal ice-liquid density has a minor impact on most

25 hydrological variables, but significantly affects soil water saturation with an averaged $5 \% \sim 15 \%$

26 error. Neglecting advective heat transport presents the least error, $5 \%$ or even much lower, in most

27 variables for a general Arctic tundra system, and can decrease the simulation time at hillslope

28 scales by $40 \% \sim 80 \%$. By challenging these commonly made assumptions, this work provides

29 permafrost hydrology modelers important context for better choosing the appropriate process 
representation for a given modeling experiment.

Copyright Statement. This manuscript has been authored by UT- Battelle, LLC under Contract No. DE-AC05-00OR22725 with the U.S. Department of Energy. The United States Government retains and the publisher, by accepting the article for publication, acknowledges that the United States Government retains a non-exclusive, paid-up, irrevocable, world-wide license to publish, or reproduce the published form of this manuscript, or allow others to do so, for United States Government purposes. The Department of Energy will provide public access to these results of federally sponsored research in accordance with the DOE Public Access Plan (http://energy.gov/downloads/doe-public-access-plan).

\section{Introduction}

Permafrost describes a state of ground which stays frozen continuously over multiple years, which may cover an entire region (e.g., Arctic tundra) or occur in isolation (e.g., alpine top). From the perspective of scope, permafrost occupies approximately $23.9 \%\left(22.79\right.$ million $\left.\mathrm{km}^{2}\right)$ of the exposed land area of the northern hemisphere (Zhang et al., 2008), as well as alpine regions and Antarctica in the southern hemisphere. Permafrost areas store a vast amount of organic carbon, of which most is stored in perennially frozen soils (Hugelius et al., 2014). If the organic carbon is exposed due to permafrost thaw, it is likely to decay with microbial activity, releasing greenhouse gas to the atmosphere and exacerbating global warming. In Arctic tundra, permafrost also plays an important role in maintaining water, habitat of wildlife, landscape, and infrastructure (Berteaux et al., 2017; Dearborn et al., 2021; Hjort et al., 2018; Sugimoto et al., 2002). Permafrost degradation may cause significant damage to the local ecosystem, reshape the surface and subsurface hydrology, and eventually influence the global biosphere (Cheng and $\mathrm{Wu}, 2007$; Jorgenson et al., 2001; Tesi et al., 2016; Walvoord and Kurylyk, 2016). Therefore, the occurrent and potential impacts motivate the development of computational models with the goal of better understanding the thermal and hydrological processes in permafrost regions, and consequently predict permafrost thaw accurately.

Simulating soil freezing and thaw processes is a challenging task that incorporates mass and energy transfer among atmosphere, snowpack, land surface (perhaps with free water), and a variably saturated subsurface. Several hydrological models with different complexity and applicable scales 
have been developed to investigate the complicated interactions. A comprehensive review of permafrost models based on empirical and physical representations using analytical and numerical solutions can be found in (Bui et al., 2020; Dall'Amico et al., 2011; Jan et al., 2020; Kurylyk et al., 2014; Kurylyk and Watanabe, 2013; Riseborough et al., 2008). Process-rich models which aim to predict permafrost change through direct simulation of mass and energy transport, such as the Advanced Terrestrial Simulator (ATS; Painter et al., 2016), GEOtop (Endrizzi et al., 2014), CryoGrid 3 (Westermann et al., 2016), PFLOTRAN-ICE (Karra et al., 2014), and SUTRA-ICE (McKenzie et al., 2007), have been demonstrated to describe thermal permafrost hydrology under various climate conditions. Nominally, representing more physical process complexity should improve accuracy, but how much accuracy and at what computational expense (and therefore tradeoff in ability to run larger, or larger ensembles of, simulations) is not always theoretically known. Thus, certain assumptions or simplifications about the system are a significant part of model development.

Even in the most process-rich models of permafrost change, three such physics simplifications are often made: representing water at constant density (thereby neglecting the expansion of ice relative to liquid water), neglecting cryosuction of water in unsaturated, partially frozen soils, and neglecting advective heat transport.

First, because of the lower density of ice than liquid water, freezing water must expand the volume of the porous media, push liquid water into nearby volume, or otherwise expand the volume occupied by that water. As all of the current set of models operate under the assumption of a rigid solid matrix and thus the absence of mechanical equations describing matrix deformation or frost heave, including this expansion typically results in large pressures that must be offset by grain compressibility or another mechanism. Therefore, the densities of ice and liquid water are frequently assumed equal (e.g., Dall'Amico et al., 2011; Devoie and Craig, 2020; Weismüller et al., 2011). It is uncertain whether this simplification affects predictions of permafrost change and thermal hydrology.

Second, cryosuction describes the redistribution of water in partially frozen, unsaturated soils caused by increased matric suction. At the interface of ice and liquid water, negative pressures result in the migration of liquid water toward the freezing front and the subsequent increase of ice content. Several approaches representing cryosuction in models are used (Dall'Amico et al., 2011; Noh et al., 2012; Painter and Karra, 2014; Stuurop et al., 2021), either in an empirical form or 
91 physically derived from the generalized Clapeyron equation. Other process-rich models have ignored cryosuction entirely (McKenzie et al., 2007; Viterbo et al., 1999). Dall'Amico et al. (2011), Painter (2011) and Painter and Karra (2014) evaluated their respective Clapeyron equation based cryosuction models in soil column freezing simulations and presented a good match between simulations and laboratory experiments in total water content (liquid and ice). Recently, Stuurop et al. (2021) applied an empirical expression, a physics-based expression, and no cryosuction in simulating soil column freezing process. They compared the simulated results with observations from laboratory experiments. This comparison demonstrated minor differences between empirical and Clapeyron-based cryosuction expressions, but the simulation without cryosuction cannot predict the distribution of total water content in a laboratory-scale soil column. To our knowledge, there is still no literature showing the effect of cryosuction on plot-scale permafrost predictions. Third, heat transport in process-rich models is described using an energy conservation equation, mainly including heat conduction, latent heat exchange, and heat advection. From a continuumscale perspective, conductive heat transport is expressed in the form of a diffusive term base on Fourier's law. Latent heat exchange accompanies phase change which alters the system enthalpy. Advective heat transport describes the energy exchange caused by the flow of liquid water driven by a hydraulic gradient (i.e., forced convection), which is expressed through an advective term in energy balance equations. Additionally, other mechanisms that control heat transport, such as water vapor movement, thermal dispersion, radiant energy, etc., are neglected by nearly all models of permafrost and are not considered here. Among these heat transport mechanisms, it is commonly recognized that heat conduction predominates heat transport in the subsurface (Nixon, 1975). However, there are also studies demonstrating the importance of advective heat transport in permafrost hydrology through field observation analysis or modeling comparison. Such

114 situations where advective heat makes important contributions roughly fall into three categories.

115 The first centers on the development of taliks beneath lakes, ponds, snowmelt water and rainfall

116 induced runoff, or in the existence of supra-/sub-permafrost groundwater flow (e.g., Luethi et al.,

117 2017; McKenzie and Voss, 2013; Rowland et al., 2011). The second focuses on microtopographic

118 features that focus significant amount of water flux through small areas. This includes both low-

119 center ice wedge polygons associated with the formation of thermokarst ponds (e.g., Abolt et al.,

120 2020; Harp et al., 2021) and thermo-erosion gullies (e.g., Fortier et al., 2007; Godin et al., 2014).

121 In these cases, large, focused flows across small spatial scales allow advective heat transport to 
dominate. The last category includes those studying the construction and maintenance of infrastructure influenced by groundwater flow (e.g., Chen et al., 2020). Thus, these studies focus on either location-specific or scale-limited problems. As McKenzie and Voss (2013) stated, whether heat advection outweighs heat conduction depends on soil permeability, topography, and groundwater availability. Relative to these special cases, we are more interested in to what extent advective heat transport associated with liquid water flow contributes to permafrost hydrologic change in a hillslope-scale or larger Arctic system.

129 To clarify the significant differences in model representations of permafrost, we investigate the

130 influence of including or not including these processes on permafrost change at plot-to-hillslope 131 scales. We take the advantage of the flexibility offered by ATS to express multiple options of process representation to implement this study in numerical experiments. For ice density, we compare simulations with and without differences in ice density relative to water density; for cryosuction, we compare simulations using a Clapyron equation-based expression and excluding the cryosuction effect; and for heat transport, we compare simulations including or neglecting advective heat transport. All comparisons are carried out across a range of Arctic climate conditions and soil properties from three different sites. Both 1D soil-column-scale and 2D hillslope-scale models are considered, in which varying hillslope geometries (i.e., convergent/divergent hillslope) and aspects (i.e., north/south) are included. The aim of this study is to provide permafrost hydrology modelers with crucial comparisons for better choosing a model representation for a given study by formally considering the tradeoff between model complexity, accuracy, and, at least for one code, performance.

\section{Theory}

144 The Advanced Terrestrial Simulator (ATS v1.2) (Coon et al., 2020) configured in permafrost mode

145 (Jan et al., 2018, 2020; Painter et al., 2016) was used to implement all numerical experiments in 146 this study. ATS is a process-rich code developed for simulating integrated surface and subsurface

147 hydrological processes, specifically capable of permafrost applications. It has been shown to 148 successfully compare to observations of seasonal soil freezing and thaw processes at different 149 scales. This includes 1D models of vertical energy transport typical of large-scale flatter regions 150 (Atchley et al., 2015), and 2D models admitting lateral flow and transport in Arctic fens (Sjöberg 151 et al., 2016), and polygonal ground (Jan et al., 2020). 
152 The permafrost configuration of ATS comprises coupled water flow and energy transfer within

\begin{abstract}
variably saturated soils and at land surfaces, a surface energy balance model describing thermal
\end{abstract} processes in snow, and a snow distribution module for surface microtopography (Painter et al., 2016). The subsurface system solves a three-phase (liquid, ice, gas), two-component (water vapor, air) Richards-type mass balance equation with Darcy's law and an advection-diffusion energy balance equation. The surface system includes an overland flow model with diffusion wave approximation, and an energy balance equation with an introduced temperature-dependent factor describing the effect of surface water freezing. The subsurface system and surface system are coupled through the continuity of pressure, temperature, and the corresponding fluxes by incorporating the surface equations as boundary conditions of the subsurface equations (Coon et al., 2020). The evolution of a snowpack and its effect on the surface energy balance is described using an energy balance approach based on a subgrid model concept that includes all major heat fluxes at the land surface. For a more detailed description of the permafrost configuration and implementation in ATS, as well as key mathematical equations, the reader is referred to Painter et al. (2016). Changes in this "most complex" model of permafrost hydrology are enabled by the Arcos multiphysics library leveraged in ATS; this allows the precise model physics to be specified and configured at runtime through the use of a dependency graph describing swappable components in the model physics (Coon et al., 2016).

\title{
2.1 Ice density
}

The density of ice $\left(\mathrm{kg} / \mathrm{m}^{3}\right)$ is represented as a Taylor series expansion in both temperature and pressure:

$\rho_{\mathrm{i}}=[a+(b+c \Delta T) \times \Delta T] \times(1+\alpha \Delta p)$

and the density of liquid water $\left(\mathrm{kg} / \mathrm{m}^{3}\right)$ is represented as:

$\rho_{1}=[a+(b+(c+d \Delta T) \times \Delta T) \times \Delta T] \times(1+\alpha \Delta p)$

where $\Delta T=T-273.15, \Delta p=p_{1}-1 \mathrm{e} 5, T$ and $p_{1}$ are temperature $(\mathrm{K})$ and liquid pressure $(>101325$

$\mathrm{Pa}$ ), respectively; and $a, b, c, d, \alpha$ are constant coefficients, listed in Table 1. Under conditions of equal density, we assume $\rho_{\mathrm{i}}=\rho_{\mathrm{l}}$.

Table 1 Coefficients in density of ice and liquid

\begin{tabular}{cccccc}
\hline & $a$ & $b$ & $c$ & $d$ & $\alpha$ \\
\hline$\rho_{\mathrm{i}}$ & 916.724 & -0.147143 & $-2.38 \mathrm{e}-4$ & - & $1.0 \mathrm{e}-10$ \\
\hline$\rho_{1}$ & 999.915 & 0.0416516 & $-1.01 \mathrm{e}-2$ & $2.06 \mathrm{e}-4$ & $5.0 \mathrm{e}-10$ \\
\hline
\end{tabular}




\subsection{Cryosuction}

181 Painter and Karra (2014) proposed a constitutive relationship for phase partitioning of water in

182 frozen soils based on Clapeyron equation and Van Genuchten model (Van Genuchten, 1980):

$183 S_{\mathrm{l}}=\left\{\begin{array}{c}S_{*}\left(-\beta \rho_{\mathrm{l}} L_{\mathrm{f}} \vartheta\right), \vartheta<\vartheta_{\mathrm{f}} \\ S_{*}\left(p_{\mathrm{g}}-p_{\mathrm{l}}\right), \vartheta \geq \vartheta_{\mathrm{f}}, \vartheta=\frac{T(\mathrm{~K})-273.15}{273.15}, \vartheta_{\mathrm{f}}=-\frac{\psi_{*}\left(1-s_{\mathrm{g}}\right)}{\beta L_{\mathrm{f}} \rho_{\mathrm{l}}}\end{array}\right.$ $s_{\mathrm{i}}=1-s_{\mathrm{l}} / S_{*}\left(p_{\mathrm{g}}-p_{\mathrm{l}}\right)$

184 where $s_{n}$ is the saturation of $n$-phase and the subscripts $n=1, \mathrm{i}, \mathrm{g}$ are liquid, ice, and gas phases, respectively; $\beta$ is a coefficient; $L_{\mathrm{f}}$ is the heat fusion of ice; $p_{n}(n=1, \mathrm{~g})$ is the pressure of $n$-phase; $S_{*}$ is the Van Genuchten model. This physically derived formulation can describe the change of matric suction in the frozen zone due to the change of ice content, and thus has the capacity to represent cryosuction.

189 Alternatively, to exclude the effect of cryosuction in this study, we used the Van Genuchten model to determine the total water content, including liquid water and ice. The liquid water content is achieved by an empirical relationship (soil-freezing characteristic curve) which describes that the liquid water content only relates to temperature through an exponent function (McKenzie et al., 2007).

$s_{\mathrm{l}}=s_{\mathrm{r}}+\left(s_{\mathrm{sat}}-S_{\mathrm{r}}\right) \exp \left[-\left(\frac{T(\mathrm{~K})-273.15}{\omega}\right)^{2}\right]$ $s_{\mathrm{i}}=S_{*}\left(p_{\mathrm{g}}-p_{\mathrm{l}}\right)-s_{\mathrm{l}}$

195 where $s_{\mathrm{r}}, S_{\mathrm{sat}}$ are saturations of liquid water at residual and saturated conditions, respectively; $\omega$ is a constant coefficient.

\section{$197 \quad 2.3$ Advective heat transport}

198 The energy conservation equation of the subsurface system is given by: $\frac{\partial}{\partial t}\left[\phi \sum_{n=1, \mathrm{i}, \mathrm{g}}\left(\rho_{n} s_{n} u_{n}\right)+(1-\phi) c_{\mathrm{v}, \text { soil }} T\right]+\underbrace{\nabla \cdot\left(\rho_{1} h_{1} \mathbf{V}_{1}\right)}_{\text {advective heat }} \underbrace{-\nabla \cdot\left(\kappa_{\mathrm{e}} \nabla T\right)}_{\text {conductive heat }}=Q_{\mathrm{E}}$

200 where $\phi$ is porosity; $u_{n}$ is the specific internal energy of phase $(n \in\{1, \mathrm{i}, \mathrm{g}\}) ; c_{\mathrm{v}, \text { soil }}\left(\mathrm{J} \mathrm{m}^{-3} \mathrm{~K}^{-1}\right)$ is the volumetric heat capacity of the soil grains. The second and third terms represent the advective and conductive heat transport in subsurface, in which $h_{1}(\mathrm{~J} / \mathrm{mol})$ is the specific enthalpy of liquid; $\mathbf{V}_{1}(\mathrm{~m} / \mathrm{s})$ is the velocity vector of liquid water determined by Darcy's law; and $\kappa_{\mathrm{e}}\left(\mathrm{W} \mathrm{m}^{-1} \mathrm{~K}^{-1}\right)$ is the effective thermal conductivity of the bulk material including soil, air, liquid water, and ice. $Q_{\mathrm{E}}$ is the sum of all thermal energy sources $\left(\mathrm{W} / \mathrm{m}^{3}\right)$.

206 Similarly, the energy balance equation of the surface system is: 
$207 \frac{\partial}{\partial t}\left\{\left[\chi \rho_{\mathrm{l}} u_{\mathrm{l}}+(1-\chi) \rho_{\mathrm{i}} u_{\mathrm{i}}\right] \delta_{\mathrm{w}}\right\}+\underbrace{\nabla \cdot\left(h_{\mathrm{l}} \chi \rho_{\mathrm{l}} \delta_{\mathrm{w}} \mathbf{U}_{\mathrm{w}}\right)}_{\text {advective heat }} \underbrace{-\nabla \cdot\left\{\left[\chi \kappa_{\mathrm{l}}+(1-\chi) \kappa_{\mathrm{i}}\right] \delta_{\mathrm{w}} \nabla T\right\}}_{\text {conductive heat }}=Q_{\text {net }}$

208 in which $\chi$ is the unfrozen fraction determined by surface temperature; $\delta_{\mathrm{w}}$ is ponded depth (m);

$209 \mathbf{U}_{w}(\mathrm{~m} / \mathrm{s})$ is the velocity vector of liquid water on the surface determined by the diffusion-wave

210 approximated St. Venant equations (Gottardi and Venutelli, 1993) and Manning equation

211 (Wasantha Lal, 1998); $\kappa_{n}\left(\mathrm{~W} \mathrm{~m}^{-1} \mathrm{~K}^{-1}\right)$ is the thermal conductivity of $n$-phase $(n=1, \mathrm{i}) ; Q_{\text {net }}\left(\mathrm{W} / \mathrm{m}^{3}\right)$

212 is the net thermal energy into and out of surface, including that from solar radiation, rain and snow

213 melt, water loss by evaporation and to the subsurface, and conductive and advected heat transport

214 to/from the subsurface. The second and third terms represent the (lateral) advective and conductive

215 heat transport that occur across the land surface.

\section{Methods}

217 To evaluate the impact of representation of ice density, cryosuction, and advective heat transport

218 in permafrost modeling under different climate conditions and soil properties, we selected three

219 sites for their variance in climactic condition: Utqiagvik (Barrow Environmental Observatory,

$\left.22071.3225^{\circ} \mathrm{N}, 156.6231^{\circ} \mathrm{W}\right)$, the headwaters of the Sagavanirktok (Sag) River $\left(68.251^{\circ} \mathrm{N}, 149.092^{\circ}\right.$

$221 \mathrm{~W})$, and the Teller Road Mile Marker 27 site on the Seward Peninsula $\left(64.73^{\circ} \mathrm{N}, 165.95^{\circ} \mathrm{W}\right)$ in

222 Alaska. The simulated hydrological outputs for each site are compared in both column and hillslope scenarios. Column scenarios represent expansive flat regions typical of the Arctic coastal plains dominated by vertical infiltration and heat transport, and hillslope scenarios are representative of the headwater, hilly terrain typical of the more inland permafrost. In hillslope scenarios, hillslopes with northern and southern aspects are considered to investigate physics representation comparisons under the same climate and soil condition (i.e., at a given site) but different solar radiation incidence. Furthermore, hillslopes with both convergent and divergent geometries are included to compare the sensitivity of simulated discharge on process representation. These scenarios can incorporate many types of Arctic systems at the described plotto-regional scales, but explicitly ignore the effects of microtopography or other local-scale focusing mechanisms such as water tracts or thermo-erosion gullies. The objective is to reach a conclusion on the influence of the three physics representation that can be widely applicable in many Arctic systems.

\section{$235 \quad 3.1$ Field data description}


236 For each site, data used in each simulation comprises meteorological forcing datasets for the period 2011-2020, averaged wind speed, and soil properties.

238 Meterological forcing datasets are taken from the Daymet version 4 dataset (Thornton et al., 2020), which provides observation-based, daily averaged weather variables through statistical modeling techniques at $1 \mathrm{~km}$ spatial resolution (Thornton et al., 2021). Variables that are used in simulations include daily average air temperature (calculated as the mean of Daymet's daily minimum and maximum values), relative humidity (calculated from air temperature and Daymet's vapor pressure), incoming shortwave radiation $\left(\mathrm{W} / \mathrm{m}^{2}\right.$ ) (calculated as a product of Daymet's daylit incoming radiation and daylength), and total precipitation $(\mathrm{m} / \mathrm{s})$, which is split into snow and rain based upon the air temperature. Figure 1 illustrates the precipitation of rain, snow, and air temperature in the three sites from 2011 to 2020, where the points represent the corresponding averaged values per year. In terms of the forcing conditions, the annual rainfall of the Sag and Teller sites range between 20 and $40 \mathrm{~mm} / \mathrm{d}$ over the ten years, more than twice the rainfall typical of the Barrow site. In addition, Sag has a significantly larger amount of snow every year that is over double of that at the Teller site and almost five times larger compared to the Barrow site. For the air temperature, Sag and Barrow are similar and colder than Teller by 7-8 degrees. In general, the Barrow site is dry and cold, the Sag site is wet and cold, and the Teller site is wet and warm.
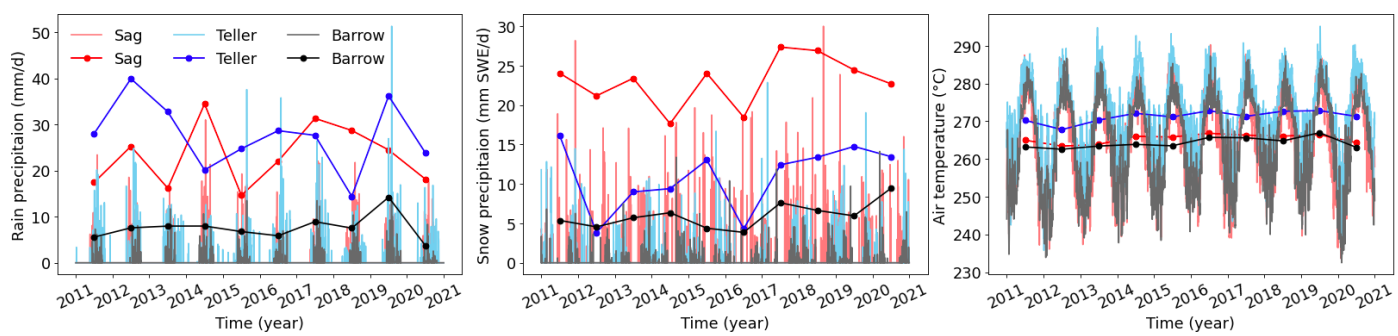

Figure 1 Precipitation and air temperature of site Barrow, Sag, and Teller from year 2011 to 2020

In addition to the time series of forcing data from Daymet, we used an average wind speed for each site. For Barrow and Teller, the average wind speed was estimated from the measurement taken by the Next-Generation Ecosystem Experiments (NGEE) Arctic project. At Barrow, the measurement was taken at area $\mathrm{A}\left(71.2815^{\circ} \mathrm{N}, 156.6108^{\circ} \mathrm{W}\right)$ at the height of 1.3 meters above surface (Hinzman et al., 2014). At Teller, the measurement at $3.8 \mathrm{~m}$ above the surface of a lower level of the watershed (Busey et al., 2017) was used. For Sag, the average wind speed was estimated based on the measurement at the Toolik Lake field site (near to Sag River) at the height 
262 of $3.1 \mathrm{~m}$ above surface, which is accessible through the National Ecological Observatory Network

263

264

265

266

267

268

269

270

271

272

273

274 (NEON, 2021).

The soil properties of Barrow, Sag, and Teller, including porosity, permeability, Van Genuchten parameters, and thermal conductivity parameters, were chosen from previous modeling studies at these sites (Atchley et al., 2015; Jafarov et al., 2018; O'Connor et al., 2020), see (Table 2). Roughly, the soil profile of each site is composed of two materials: the top organic-rich layer comprising mosses, peats, and other organic rich soils measuring approximately 10-30 $\mathrm{cm}$ thick, and the principal mineral soil. There is minor difference in thermal conductivity parameters among the three sites, and soil permeability is also at the same order of magnitude. The soil-water characteristic curve (SWCC) of the principal mineral soil of Barrow, Sag, and Teller, shown in Figure 2, indicates that the soil property between Barrow and Teller is relatively similar, while Sag differs from the other two with a relatively flat SWCC.

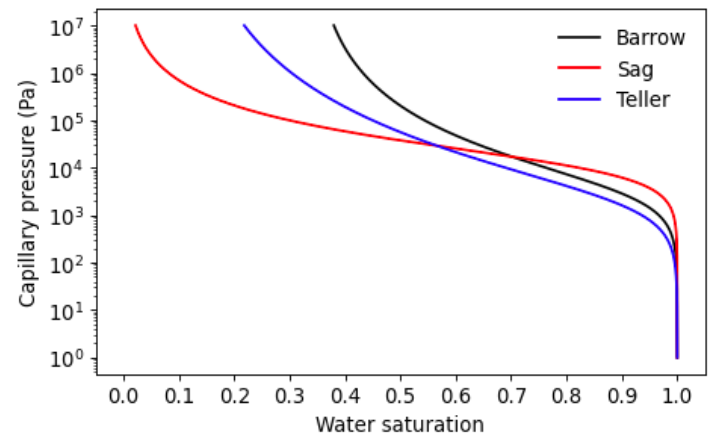

Figure 2 Soil-water characteristic curve (SWCC) of soil in Barrow, Sag, and Teller

Usually, at the hillslope scale, the thickness of organic layers of a watershed varies from the toeslope, through a steeper mid-hill, up to the flat top. Typically, thicker organic layers may exist at the top and bottom compared to the mid-hillslope. The low thermal conductivity of organic layers can impede the heat transport between the air and the underlying mineral soil, resulting in varying thaw depth (or permafrost table depth) along a hillslope, which has been observed at the site Teller (Jafarov et al., 2018). In this paper, hillslope meshes were constructed following this observation so that the organic layers are thicker at the top and bottom of a hillslope, as described in the next section.

\subsection{Mesh design and material properties}

The comparison of different physics representations was conducted in both column and hillslope 
scenarios.

287 The column model was designed as a one-dimensional, $50 \mathrm{~m}$ deep domain. The column domain was discretized into 78 cells with gradually increasing cell thickness, starting from $2 \mathrm{~cm}$ at the soil surface to $2 \mathrm{~m}$ at the bottom of the domain. We assigned different material properties to the cells to represent different soil layers. A column domain is divided into three layers, and the thickness of each layer was designed differently among the three sites according to geological observations (Jan et al., 2020; O'Connor et al., 2020; NGEE-Arctic). Specifically, from top to bottom, the three layers of the Barrow soil column are $2 \mathrm{~cm}$-thick moss, $8 \mathrm{~cm}$-thick peat, and mineral; for Teller, the soil column consists of a $4 \mathrm{~cm}$ moss layer, a $22 \mathrm{~cm}$ peat layer, and mineral; and the three layers of the Sag soil column are acrotelm, catotelm, with thickness of $10 \mathrm{~cm}$ and $14 \mathrm{~cm}$, respectively, and the remainder mineral. The soil properties of each layer at three sites are listed in Table 2.

Table 2 Soil properties of three soil layers of all sites used in this paper

\begin{tabular}{lccc|ccc|ccc}
\hline Site & \multicolumn{3}{c}{ Barrow } & \multicolumn{3}{c}{ Sag } & \multicolumn{3}{c}{ Teller } \\
\hline Layers & moss & peat & mineral & acrotelm & catotelm & mineral & moss & peat & mineral \\
\hline Porosity & 0.9 & 0.876 & 0.596 & 0.878 & 0.796 & 0.457 & 0.9 & 0.55 & 0.45 \\
\hline Permeability $\left(\mathrm{m}^{2}\right)$ & $1.7 \mathrm{e}-11$ & $9.38 \mathrm{e}-12$ & $6 \mathrm{e}-13$ & $2.64 \mathrm{e}-10$ & $9.63 \mathrm{e}-12$ & $3.98 \mathrm{e}-13$ & $5 \mathrm{e}-11$ & $5 \mathrm{e}-12$ & $2 \mathrm{e}-13$ \\
\hline $\mathrm{VG} \alpha\left(\mathrm{Pa}^{-1}\right)$ & $2.3 \mathrm{e}-3$ & $9.5 \mathrm{e}-4$ & $3.3 \mathrm{e}-4$ & $7.93 \mathrm{e}-4$ & $1.75 \mathrm{e}-4$ & $8.06 \mathrm{e}-5$ & $2.35 \mathrm{e}-3$ & $2.93 \mathrm{e}-4$ & $5.45 \mathrm{e}-4$ \\
\hline $\mathrm{VG} \mathrm{n}$ & 1.38 & 1.44 & 1.33 & 1.405 & 1.566 & 1.571 & 1.38 & 1.269 & 1.236 \\
\hline Residual saturation & 0.056 & 0.388 & 0.334 & 0.0073 & 0.0662 & 0. & 0.1 & 0. & 0.1 \\
\hline $\begin{array}{l}\text { Thermal conductivity, } \\
\text { unfrozen }\left(\mathrm{Wm}^{-1} \mathrm{~K}^{-1}\right)\end{array}$ & 0.446 & 0.427 & 0.788 & 0.519 & 0.630 & 1.309 & 0.57 & 0.67 & 1 \\
\hline $\begin{array}{l}\text { Thermal conductivity, } \\
\text { dry }\left(\mathrm{Wm}^{-1} \mathrm{~K}^{-1}\right)\end{array}$ & 0.024 & 0.025 & 0.104 & 0.066 & 0.086 & 0.265 & 0.07 & 0.07 & 0.29 \\
\hline
\end{tabular}

298

299 In the hillslope scenario, we designed the mesh based on observations at Teller to represent a 300 generalized, varying-thickness low Arctic hillslope. A hillslope mesh was created first by 301 generating a pseudo-2D surface mesh with 50 cells and then extruding the 2D mesh downward by

$30250 \mathrm{~m}$. The pseudo-2D surface was designed in a trapezoidal shape with a single, variable-width

303 cell in the cross-slope direction to represent convergent/divergent hillslopes, the short and long 304 sides of which are $200 \mathrm{~m}$ and $800 \mathrm{~m}$, respectively (see Figure 3). Vertically, from surface 305 downward, the grid size distribution was the same as the column mesh for each site. The domain 306 is also composed of three layers, same as the column, while the numbers of cells representing each 307 soil layer (i.e., soil layer thickness) are different along the hillslope. The thickness distribution of 308 the first two layers of each site is shown in Table 3. The third layer of a hillslope for all sites is the 309 principal mineral soil. Additionally, hillslope meshes with different aspects (i.e., north, south) were 


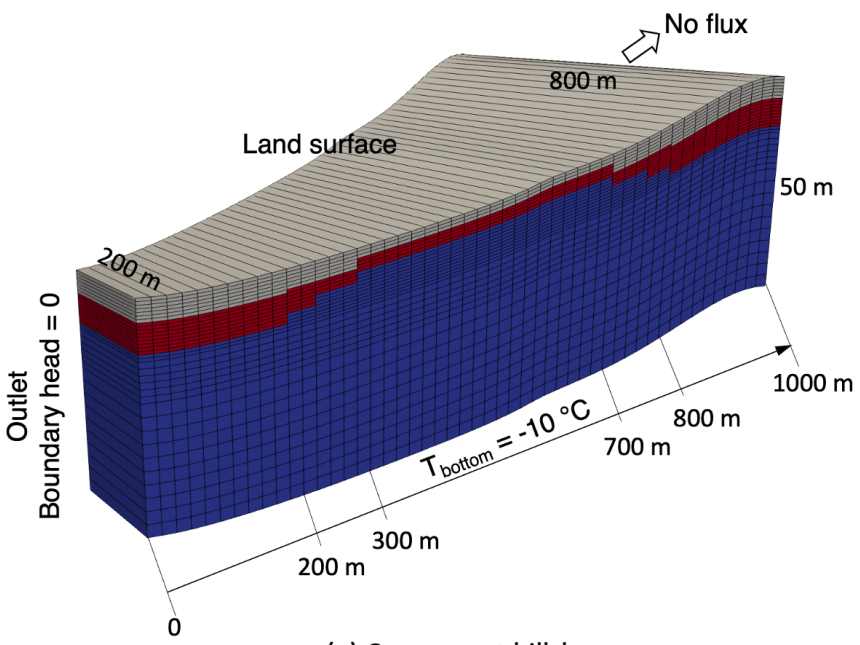

(a) Convergent hillslope

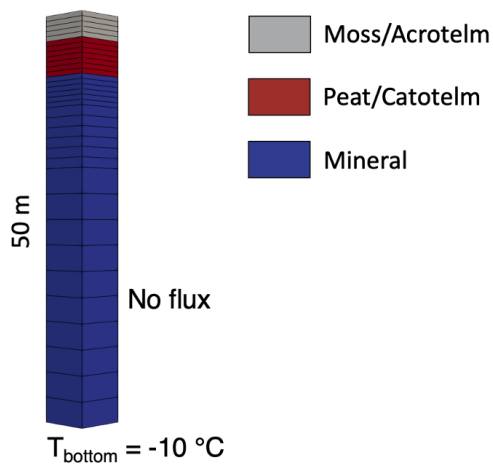

Figure 3 Schematic domain mesh and soil layer partition: (a) example of a convergent hillslope domain, (b) column domain.

Table 3 Thickness distribution of the organic layers along hillslope for each site

\begin{tabular}{ccccc}
\hline \multirow{2}{*}{ Site } & $\begin{array}{c}\text { Horizontal } x \\
\text { range }(\mathrm{m})\end{array}$ & $\begin{array}{c}\text { Barrow } \\
\text { layer thickness }(\mathrm{cm})\end{array}$ & $\begin{array}{c}\text { Sag } \\
\text { layer thickness }(\mathrm{cm})\end{array}$ & $\begin{array}{c}\text { Teller } \\
\text { layer thickness }(\mathrm{cm})\end{array}$ \\
\hline \multirow{2}{*}{$\begin{array}{c}\text { Layer 1 } \\
\text { Moss/Acrotelm }\end{array}$} & $0 \sim 200$ & 2 & 14 & 8 \\
\cline { 2 - 5 } & $300 \sim 700$ & 2 & 6 & 4 \\
\hline \multirow{2}{*}{$\begin{array}{c}\text { Layer 2 } \\
\text { Peat/Catotelm }\end{array}$} & $00 \sim 1000$ & 2 & 14 & 8 \\
\cline { 2 - 5 } & $300 \sim 700$ & 12 & 18 & 22 \\
\cline { 2 - 5 } & $800 \sim 1000$ & 12 & 18 & 22 \\
\hline
\end{tabular}

\section{3.3 Model setup}

316 To study how the representations of the three physical processes (i.e., ice density, cryosuction, and

317 advective heat transport) affect simulated hydrological outputs at different scales and hillslope

318 topography features, and under various forcing and soil conditions, 62 model simulations were

319 conducted, summarized in Table 4. To examine the validity of the assumption of equal density

320 between ice and liquid, we included cryosuction and advective heat transport in models. To

321 investigate the role of cryosuction in permafrost modeling, we used different density, while

322 neglecting advective heat transport to decrease the computation cost. Note that neglecting

323 advective heat transport in these runs can reduce the effect of cryosuction on simulation predictions,

324 as cryosuction moves water which would itself advect energy. To compare the difference between

325 neglecting and including heat advection, we used different density expressions for ice and liquid, 
326 and included cryosuction. Particularly, in order to understand the impact of advective heat

327 transport on permafrost process when soil is at its wettest, we designed two extreme cases under

328 the warm, wet conditions of the Teller site in which soil evaporation was artificially reduced.

329 These runs were designed to maximize water flux and therefore maximize the potential for

330 advective heat transport to affect predictions.

Table 4 Ensemble of models designed in this study

\begin{tabular}{|c|c|c|c|c|c|}
\hline To compare & Site & Scale & Geometry & Aspect & Remark \\
\hline \multirow{3}{*}{$\begin{array}{l}\text { - } \rho_{\mathrm{i}} \neq \rho_{\text {l, Eq. }}(1) \\
\text { - } \rho_{\mathrm{i}}=\rho_{\mathrm{l}} \text {, Eq. }(2)\end{array}$} & \multirow{3}{*}{$\begin{array}{l}\text { Barrow } \\
\text { Sag } \\
\text { Teller }\end{array}$} & column & - & - & \multirow{3}{*}{$\begin{array}{l}\text { - heat advection } \\
\text { - cryosuction }\end{array}$} \\
\hline & & \multirow[b]{2}{*}{ hillslope } & convergent & $\begin{array}{l}\text { north } \\
\text { south }\end{array}$ & \\
\hline & & & divergent & $\begin{array}{l}\text { north } \\
\text { south }\end{array}$ & \\
\hline \multirow{4}{*}{$\begin{array}{l}\text { - Include heat transport } \\
\text { - Neglect heat transport }\end{array}$} & \multirow{3}{*}{$\begin{array}{l}\text { Barrow } \\
\text { Sag } \\
\text { Teller }\end{array}$} & column & - & - & \multirow{3}{*}{$\begin{array}{l}\text { - } \rho_{\mathrm{i}} \neq \rho_{1} \\
\text { - cryosuction }\end{array}$} \\
\hline & & \multirow[b]{2}{*}{ hillslope } & convergent & $\begin{array}{l}\text { north } \\
\text { south }\end{array}$ & \\
\hline & & & divergent & $\begin{array}{l}\text { north } \\
\text { south }\end{array}$ & \\
\hline & Extreme case, Teller & hillslope & convergent & north & - reduced evaporation \\
\hline \multirow{3}{*}{ - Include cryosuction } & \multirow{3}{*}{$\begin{array}{l}\text { Barrow } \\
\text { Sag } \\
\text { Teller }\end{array}$} & column & - & - & \multirow{3}{*}{$\begin{array}{l}-\rho_{\mathrm{i}} \neq \rho_{\mathrm{l}} \\
\text { - no heat advection }\end{array}$} \\
\hline & & \multirow{2}{*}{ hillslope } & convergent & $\begin{array}{l}\text { north } \\
\text { south }\end{array}$ & \\
\hline & & & divergent & $\begin{array}{l}\text { north } \\
\text { south }\end{array}$ & \\
\hline
\end{tabular}

333 Prior to simulating all cases, two steps of initialization are carried out for each site. First, a column

334 model with a given initial water table depth and above- $0{ }^{\circ} \mathrm{C}$ temperature was frozen by setting the

335 bottom temperature at a constant value of $-10{ }^{\circ} \mathrm{C}$ until a steady-state frozen soil column is formed.

336 The initial water table depth is chosen to ensure that the frozen column's water table, after

337 accounting for expansion of ice, is just below the soil surface. The pressure and temperature

338 profiles of the frozen column were used as the initial conditions of the second step initialization.

339 Before proceeding, the observed forcing data (period of 2011-2020) was averaged across the years

340 to form a one-year, "typical" forcing year, which was then repeated 10 times. Using this typical

341 forcing data and the solutions of the first step, we solved the column model in a transient solution,

342 calculating an annual cyclic steady-state and obtaining the pressure and temperature fields at the

343 end of the $10^{\text {th }}$ year. The final state was then used as initial condition in formal simulations listed

344 in Table 4 . The temperature at bottom was constant at $-10^{\circ} \mathrm{C}$.

\section{$345 \quad 3.4$ Evaluation metrics}


346 To fully assess the effect of representation of ice density, advective heat transport, and cryosuction

347 in permafrost hydrology modeling, we used root mean squared error (RMSE) and normalized

348 Nash-Sutcliffe efficiency (NNSE) as performance metrics. RMSE has the same dimension with

349 the corresponding variables, which can be used to evaluate the average absolute deviation from a

350 benchmark, defined by:

$351 \quad$ RMSE $=\sqrt{\frac{\sum_{t=1}^{N}\left(x_{t}-y_{t}\right)^{2}}{N}}$

352 where $x_{t}$ and $y_{t}$ are the two modeled datasets to compare from the initial time point $(t=1)$ to the 353 end $(t=N)$.

354 NNSE is a normalized dimensionless metric describing the relative relationship between an

355 estimation and a reference, which is oftentimes used for evaluating hydrological models.

$356 \quad$ NNSE $=1 /\left(1+\frac{\sum_{t=1}^{N}\left(x_{t}-y_{t}\right)^{2}}{\sum_{t=1}^{N}\left(x_{t}-\bar{x}\right)^{2}}\right)$

357 where the modeled results $x_{t}$ (obtained without physics simplification) is considered as the

358 benchmark, and $\bar{x}$ is the mean value of the benchmark. NNSE approaching to 1 indicates perfect

359 correspondence between two observations.

360 In addition, we also used normalized mean absolute error (MAE) to quantify the percentage change

361 of results obtained with simplified physics relative to full physical representations (see Section

$3624.4)$.

363 Normalized MAE $=\frac{\sqrt{\sum_{t=1}^{N}\left|x_{t}-y_{t}\right| / N}}{\text { normalizing reference }} \times 100 \%$

364 Two normalizing references were selected considering different model output variables. For

365 instance, in terms of temperature and saturation which fluctuate between two non-zero values, the

366 annually averaged variation range was chosen as the reference.

367 Normalizing reference $=\frac{\sum_{\text {year }=1}^{\text {num of years }}(\text { maximum }- \text { minimum })}{\text { number of years }}$

368 For variables with zero as the smallest value, such as evaporation, discharge, and thaw depth, the corresponding average value was selected as the reference.

\section{$370 \quad 4$ Results}

371 This section compares simulated outputs over the period of 2011-2020 for the three physics under

372 different simulating conditions. We focus on the impact on integrated variables, such as

373 evaporation, discharge, averaged thaw depth, and depth-dependent variables, such as temperature, 
374 and total water saturation (ice and liquid). For hillslope models, we chose five surface locations 375 according to the slope geometry to collect simulated data, which were then averaged to obtain a 376 single outcome for each variable of interest.

\section{$377 \quad 4.1$ Ice density}

378 To evaluate the representation of ice density on permafrost process simulation, we compared evaporation, discharge, thaw depth, and total water saturation between simulations using equal and different ice density expressions. Figure 4 and Figure 5 show an example of the comparison under conditions of Sag at column and hillslope scale, respectively. Results are compared in both time series and correlation.

Generally, at both column and hillslope scale, assuming equal density between ice and liquid has minor impacts on evaporation, discharge, and thaw depth over the 10-year simulation, except at a few deviated points as shown in the correlation figures. According to column-based models, the RMSEs of evaporation, discharge, and thaw depth are $0.101 \mathrm{~mm} / \mathrm{d}, 0.001 \mathrm{~m}^{3} / \mathrm{d}$, and $1.648 \mathrm{~cm}$, respectively, one order of magnitude smaller than the corresponding variable values. At hillslope scale, see Figure 5, the south-facing divergent hillslope is selected to show modeling comparison on evaporation and thaw depth, in that they are potentially mostly affected when a hillslope has a south orientation and divergent geometry. Likewise, the north-facing convergent hillslope is chosen to compare discharge and water saturation from simulations with different density expression. Even then, RMSEs of the three variables are $0.064 \mathrm{~mm} / \mathrm{d}, 111.073 \mathrm{~m} / \mathrm{d}$, and $0.825 \mathrm{~cm}$, respectively, two orders of magnitude smaller than the corresponding variable values at hillslope scale. Besides, NNSEs of the three variables output from both column and hillslope simulation are over 0.9 , approaching 1 especially at the hillslope scale. Therefore, all indicate good performance of equal ice-liquid density assumption in predicting integrated variables and thaw depth. By comparison, the estimation of water saturation is relatively affected by the density assumption during cold seasons within a year, as shown by Figure 4 (d) and Figure 5 (d). This is reasonable in that when water mainly exists in the form of ice, equal ice-liquid density assumption will overestimate the water content. 

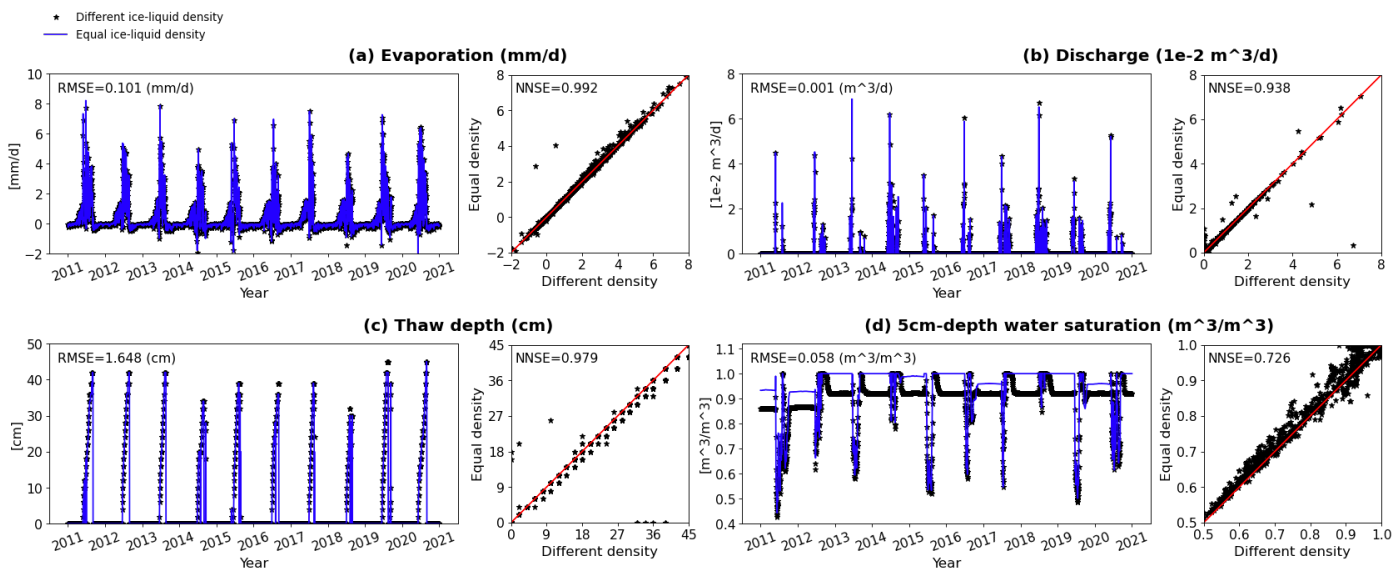

Figure 4 Comparison of column simulations between different and equal ice-liquid density under conditions of Sag, in (a) evaporation, (b) discharge, (c) thaw depth, and (d) water saturation at $5 \mathrm{~cm}$ beneath surface from year 2011 to 2020.
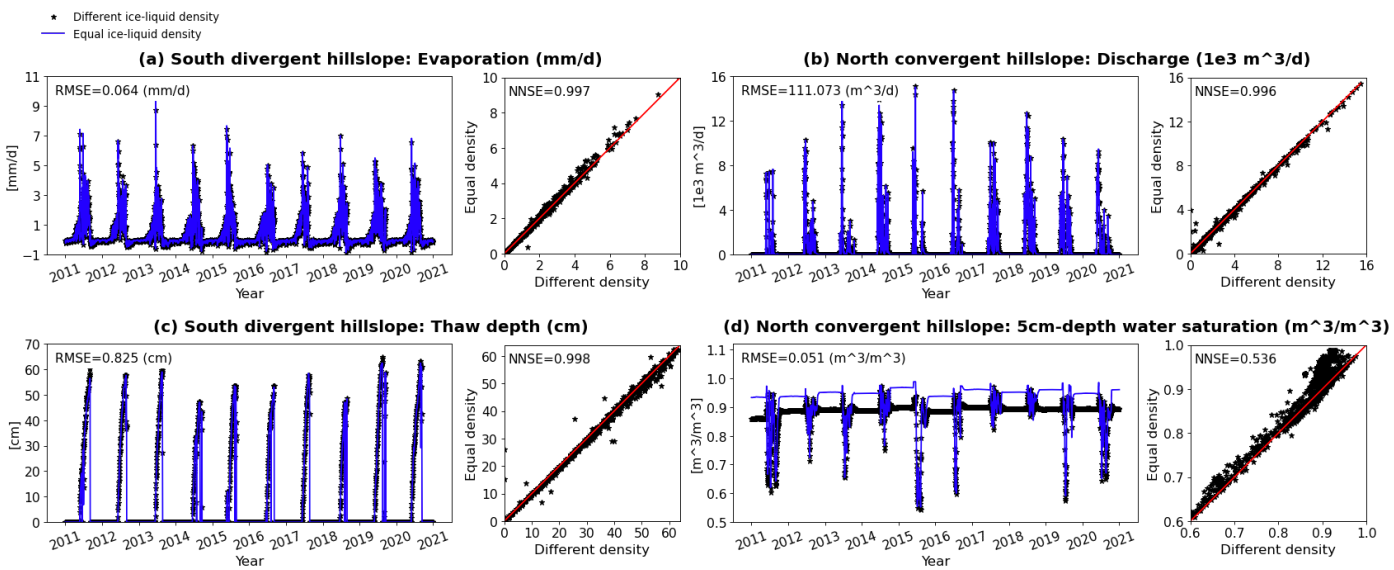

Figure 5 Comparison of hillslope simulations between using different and equal ice-liquid density under conditions of Sag, in (a) evaporation, (b) discharge, (c) thaw depth, and (d) water saturation at $5 \mathrm{~cm}$ beneath surface from year 2011 to 2020.

In addition, we investigated how much the assumption of equal ice-liquid density can affect simulation time at hillslope scale. Using 10-year simulations with real ice density as references, the percentage change of time consumed after applying equal ice-liquid density was calculated and displayed in Figure 6. Overall, under the density assumption, it may take less time (positive percentage), but no more than $25 \%$ and on average lower than $10 \%$. However, it may also increase computational time (negative percentage) mainly under wet conditions, such as at Sag and Teller. Thus, given a long-period large-scale modeling of permafrost freezing and thaw process, there is no consistent conclusion on whether equal ice-liquid density can ease computational cost. It 
417 depends on both the weather conditions and soil properties.

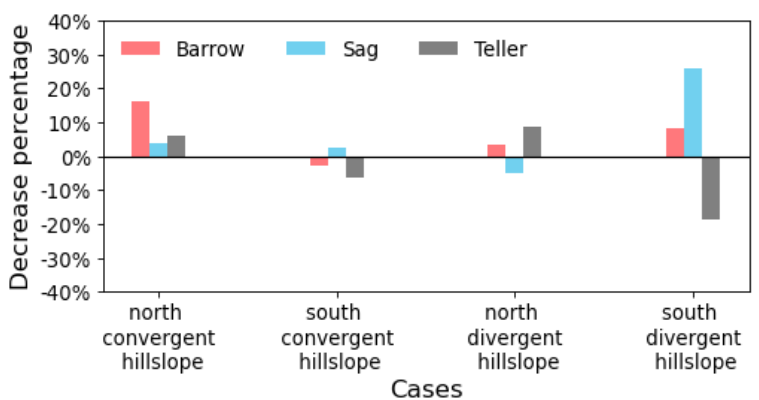

Figure 6 Decreased percentage of simulation time under the assumption of equal ice-liquid density compared to the real ice density representation for all hillslope scale simulations.

\subsection{Cryosuction}

422 To evaluate the effect of cryosuction on permafrost process predictions, we compared evaporation,

423 discharge, thaw depth, total water saturation, and temperature obtained through simulations

424 including and neglecting cryosuction. Figure 7 through Figure 9 illustrate column-scale 425 comparisons of these variables under conditions at three sites (Barrow, Sag, and Teller). Figure 7 426 presents the effect of excluding cryosuction on evaporation and discharge. RMSE of evaporation 427 from the three sites ranges between $0.25 \mathrm{~mm} / \mathrm{d}$ and $0.35 \mathrm{~mm} / \mathrm{d}$, still one order of magnitude smaller 428 than the common evaporation rate. Evaporation NNSEs of the three sites are around 0.9. For 429 discharge, RMSEs are also one order of magnitude smaller than the average, whereas NNSEs fall 430 between 0.6 and 0.9 . Generally, cryosuction plays a more important role in predicting discharge 431 compared to evaporation, especially under warm and wet climate conditions, such as Teller. 

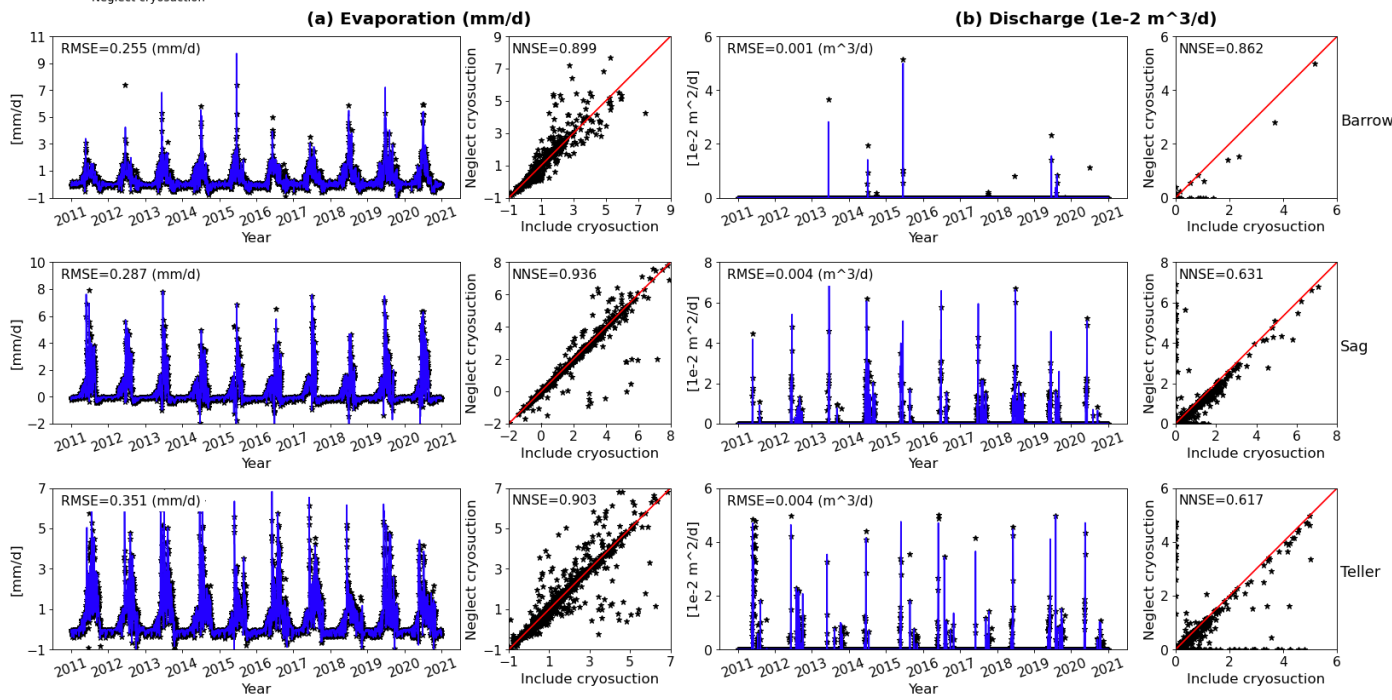

Figure 7 Comparison of column simulations between including and neglecting cryosuction under conditions of Barrow, Sag, and Teller, in (a) evaporation, (b) discharge.

435 Figure 8 shows the effect of cryosuction on column-scale simulated thaw depth and total water saturation at $5 \mathrm{~cm}$ beneath surface. RMSEs of thaw depth range from $3 \mathrm{~cm}$ to $8 \mathrm{~cm}$. Though still one order of magnitude smaller than the average annual thaw depth, the estimation error due to neglecting cryosuction is obvious in summer, especially at areas with cold temperature and low rainfall like Barrow. By comparison, at Teller, where the largest thaw depth is over double of Barrow and Sag due to its higher temperature, soil cryosuction does not essentially affect thaw depth compared to the other two sites. Similarly, for the total water saturation, at Barrow, the effect of cryosuction is more clearly observed, not only during cold seasons as observed for density representation (section 4.1), but also in summers. 

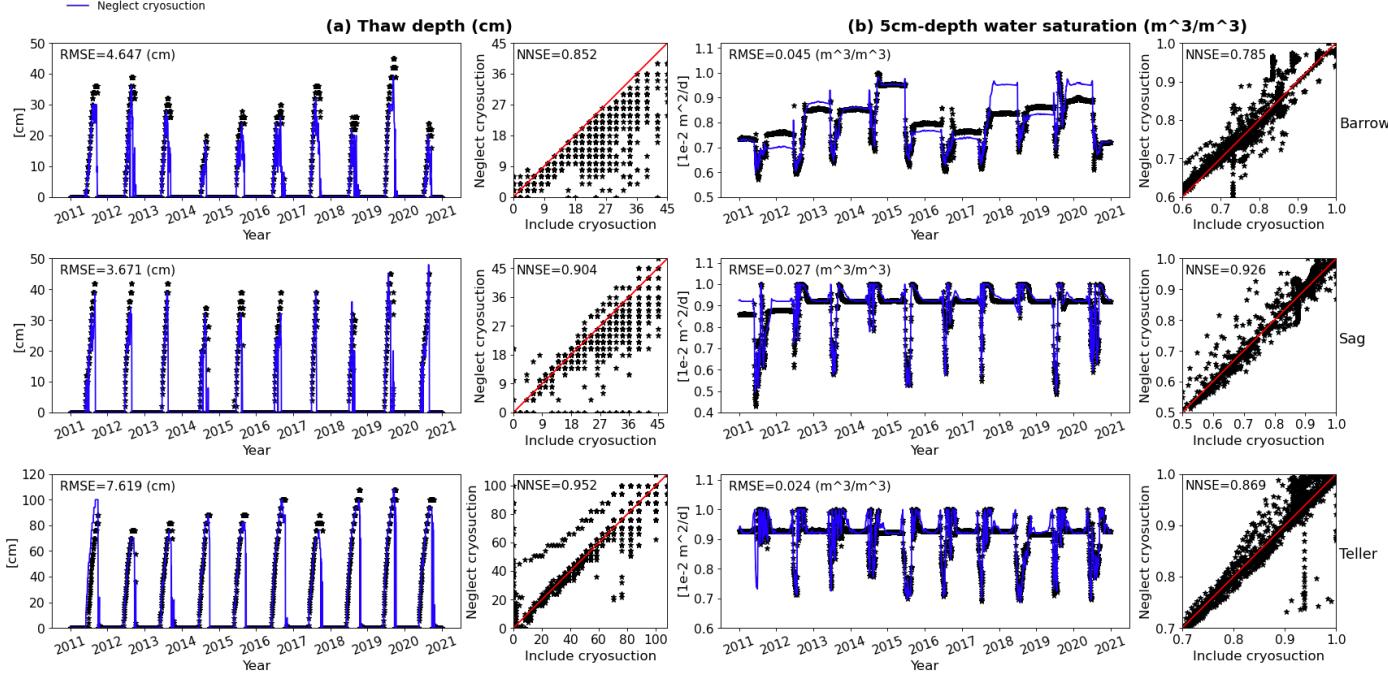

Figure 8 Comparison of column simulations between including and neglecting cryosuction under conditions of Barrow, Sag, and Teller, in (a) thaw depth, (b) water saturation at $5 \mathrm{~cm}$ beneath surface.

Finally, we also compared soil temperature obtained from models with or without cryosuction included; see Figure 9. Surface temperature is little affected by cryosuction, except at the Sag site, where the surface temperature is overestimated during winter. At $1 \mathrm{~m}$ depth, soil temperature of Barrow is slightly changed in summer due to neglecting cryosuction. At both Sag and Teller, the fluctuation range of temperature at $1 \mathrm{~m}$ beneath land surface is underestimated if cryosuction effect is not considered, especially at Sag, NNSE decreases to 0.6 approximately. Therefore, from Figure 7 to Figure 9, neglecting cryosuction effect at column scale simulation has less impact on integrated hydrological variables, but will cause significant difference when estimating thaw depth and location-based variables. The difference among variables varies under different climate conditions. Influence on integrated variables, such as evaporation and discharge, are more obviously under warm and wet conditions (Teller); thaw depth and water saturation are affected more under cold and low-rainfall conditions (Barrow); and soil temperature tends to be influenced greater under cold and high precipitation (rain and snow) conditions (Sag). 

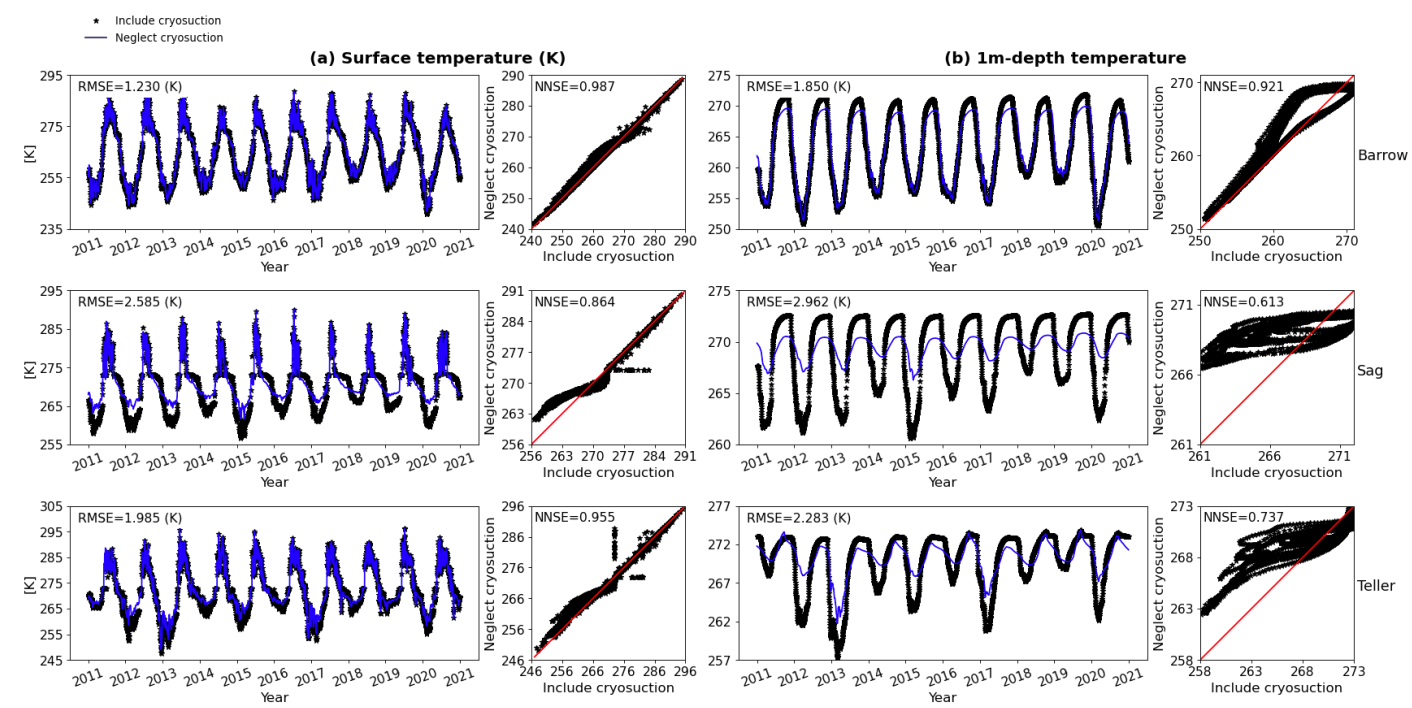

Figure 9 Comparison of column simulations between including and neglecting cryosuction under conditions of Barrow, Sag, and Teller, in (a) surface temperature, (b) temperature at $1 \mathrm{~m}$ beneath surface.

Neglecting soil cryosuction has a similar impact on hydrological outputs in hillslope scale models.

Figure 10 shows the comparison of the variables discussed above under the Sag climate.

Evaporation, thaw depth, and temperature are presented based on south-facing divergent hillslope models, while discharge and water saturation are from hillslope models with north-facing convergent geometry. In general, neglecting soil cryosuction has a smaller effect on integrated variables (evaporation and discharge) compared with other pointwise variables. Though thaw depth presents a high NNSE, approximately 0.94 , and low RMSE, about $4.5 \mathrm{~cm}$ compared to the average, indicating a good match between models considered and excluded cryosuction, the estimation error during summer may reach as high as $10 \mathrm{~cm}$, particularly from 2011 to 2017, as shown in Figure 10 (c). Obvious errors in water saturation and temperature, similar with columnscale models, occur almost annually with respect to extrema during winter and summer. Overall, compared to column-scale models, differences in evaporation, discharge, thaw depth, and surface temperature due to neglecting cryosuction effect are relatively reduced at hillslope scale if comparing NNSEs (Table 5). Localized subsurface variables, such as water saturation and 1mdepth soil temperature, show increased errors from column to hillslope scale models, which is primarily caused by lateral flux exchange captured by hillslope modeling. 

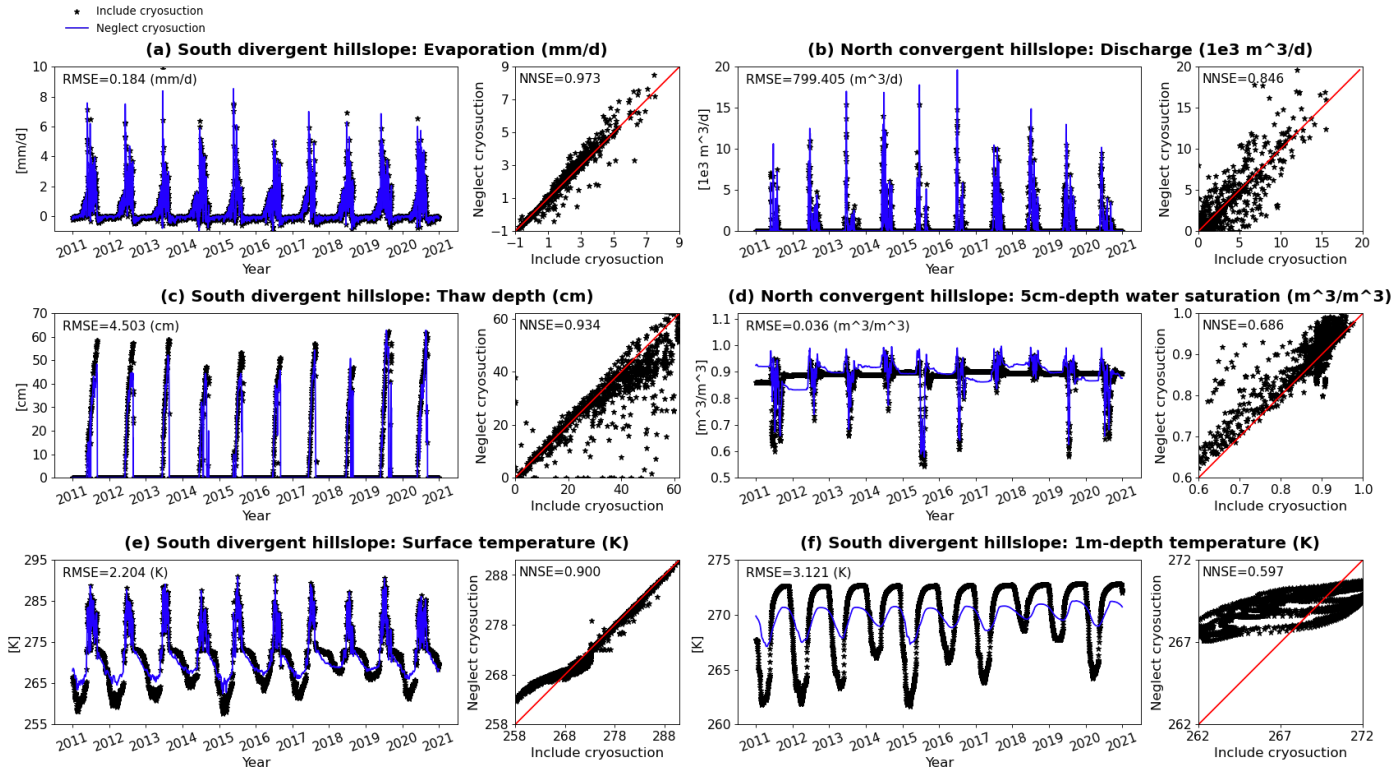

Figure 10 Comparison of hillslope simulations between including and neglecting cryosuction under conditions of Sag, in (a) evaporation, (b) discharge, (c) thaw depth, (d) water saturation at $5 \mathrm{~cm}$ beneath surface, (e) surface temperature, (f) temperature at $1 \mathrm{~m}$ beneath surface.

Table 5 NNSE of outputs from column and hillslope models under conditions of Sag shown in Figure 7 through Figure 10

\begin{tabular}{ccccccc}
\hline Scale & $\begin{array}{c}\text { Evaporation } \\
(\mathrm{mm} / \mathrm{d})\end{array}$ & $\begin{array}{c}\text { Discharge } \\
\left(\mathrm{m}^{3} / \mathrm{d}\right)\end{array}$ & $\begin{array}{c}\text { Thaw depth } \\
(\mathrm{cm})\end{array}$ & $\begin{array}{c}\text { 5cm-depth water } \\
\text { saturation }(-)\end{array}$ & $\begin{array}{c}\text { Surface } \\
\text { temperature }(\mathrm{K})\end{array}$ & $\begin{array}{c}\text { 1m-depth } \\
\text { temperature }(\mathrm{K})\end{array}$ \\
\hline Column & 0.936 & 0.631 & 0.904 & 0.926 & 0.864 & 0.613 \\
\hline Hillslope & 0.973 & 0.846 & 0.934 & 0.686 & 0.900 & 0.597 \\
\hline
\end{tabular}

\subsection{Advective heat transport}

This section evaluates the performance of advective heat transport in modeling permafrost process.

As above, we investigated the influence of neglecting heat advection on evaporation, discharge, thaw depth, total water saturation, and temperature. Overall, heat advection does not play a vital role in a normal Arctic system after comparing all hydrological outputs from models with different heat transport representations. Comparisons based on column-scale and hillslope-scale models are not shown here (see Supplement); instead, the extreme case under conditions of Teller is presented (Figure 11). Teller is abundant in rainfall over the period of 2011-2020 (Figure 1). In the extreme case, evaporation was reduced factitiously to almost a quarter of the original value (see Figure 7 (a) at Teller and Figure 11 (a)) for the purpose of increasing water flow rates. For instance, discharge has quadrupled after adjusting evaporation by comparing Figure 11 (b) and Figure 7 (b) 
at Teller. This specific scenario is chosen to maximize the potential effect of advective heat transport in a hillslope-scale Arctic system. Figure 11 illustrates comparisons on all outputs mentioned above from hillslope models without heat advection and with full thermal representation. Apparently, all RMSEs are extremely small, at least two orders of magnitude lower than the corresponding variable average. Almost all NNSEs are approximately one, even for thaw depth, localized water saturation, and temperature. Therefore, for most Arctic systems at this scale, it is reasonable to neglect advective heat transport.
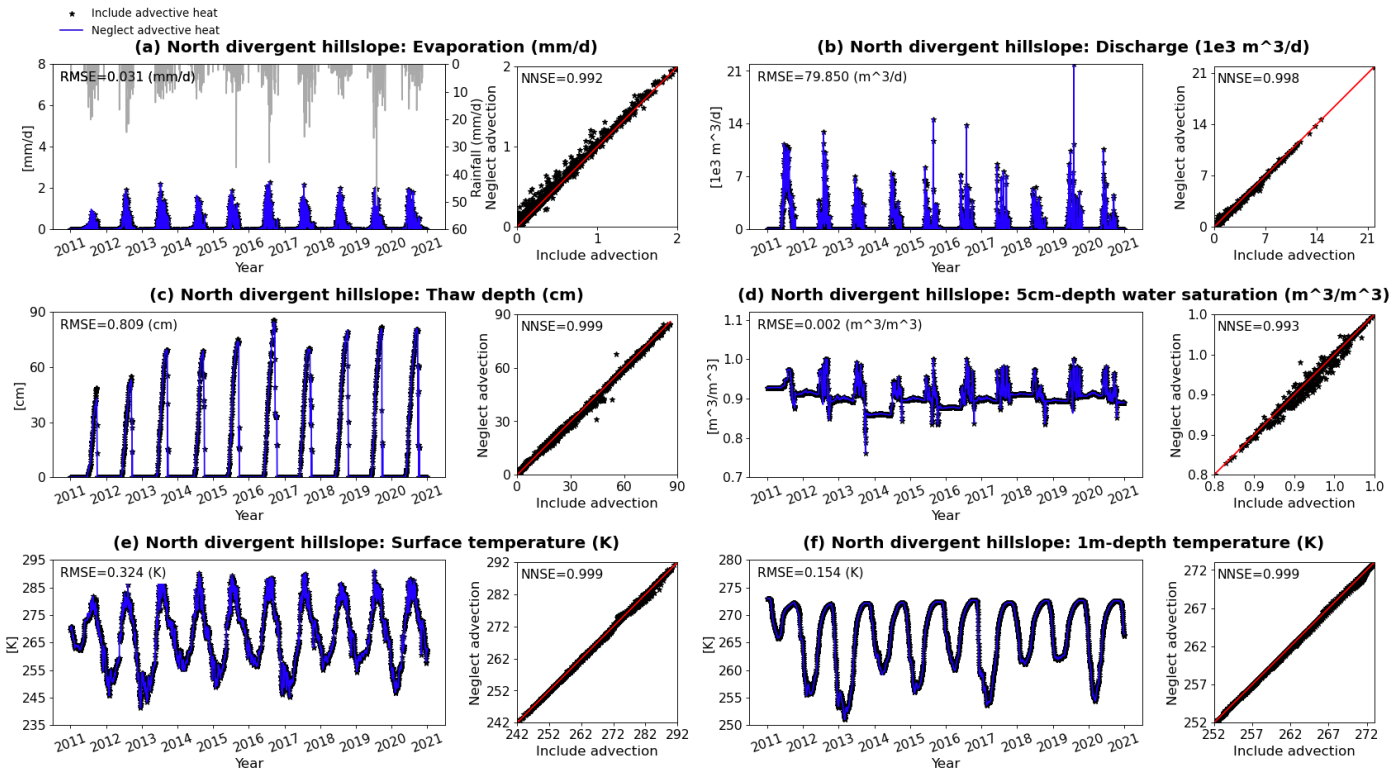

Figure 11 Comparison of hillslope simulations between including and neglecting advective heat transport under extreme conditions of Teller, in (a) evaporation, (b) discharge, (c) thaw depth, (d) water saturation at 5 $\mathrm{cm}$ beneath surface, (e) surface temperature, (f) temperature at $1 \mathrm{~m}$ beneath surface.

In addition to simulated results, we also compared simulation times in percentage change between hillslope models neglecting and including heat advection. ATS uses Algebraic Multigrid method as preconditioner for solving, which has a relatively deficient performance in dealing with hyperbolic equations. Thus, incorporating advective heat transport will aggravate computational cost, particularly in case of both large spatial and temporal scale. Figure 12 shows the relative percentage reduction in computational time for 10-year simulations after excluding heat advection in both surface and subsurface thermal flux. It drops by $70 \% \sim 80 \%$ under wet conditions (e.g.,

515 Sag and Teller) and 40\% 60\% under dry conditions (e.g., Barrow). Hence, neglecting advective

516 heat transport considerably improves the performance of large spatial-temporal permafrost 
517 hydrology simulations.

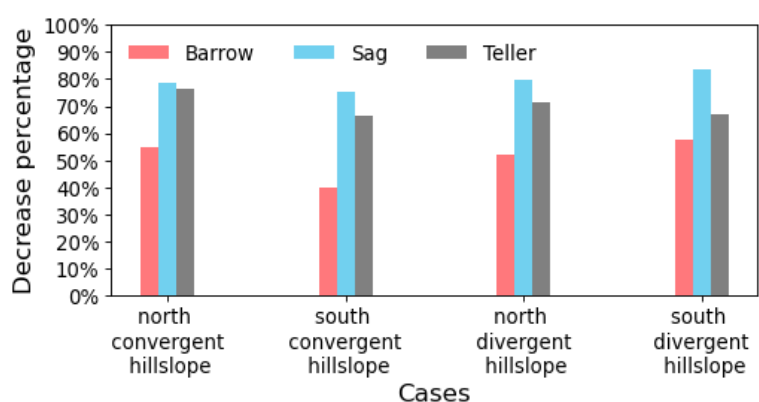

Figure 12 Decreased percentage of simulation time after neglecting heat advection compared to full thermal representation for all hillslope scale simulations.

\subsection{Comprehensive comparison}

In the above three sections, we discussed time-series simulation comparisons. This section will analyze the effect of equal ice-liquid density, neglecting cryosuction, and neglecting heat advection on permafrost modeling outputs from holistic, average perspectives.

First, we extracted NNSEs of all variables obtained from all comparing models for qualitative analysis. Table 6 shows an example based on column-scale models under conditions of three different sites. Red numbers highlight the obviously reduced NNSEs of one or two processes among the three for each variable. Overall, neglecting advective heat transport has the least influence on model outputs. Equal ice-liquid density primarily affects saturation and has less effect on other variables. Excluding soil cryosuction makes the greatest impact on almost all variables, especially in a relatively wet environment. Among the variables, evaporation and surface temperature are less affected by the three physical process representations, while location-based water saturation is most affected.

\begin{tabular}{lccc|ccc|ccc}
\hline \multirow{2}{*}{ Variables } & \multicolumn{4}{c|}{ Barrow } & \multicolumn{3}{c}{ Sag } & \multicolumn{3}{c}{ Teller } \\
\cline { 2 - 12 } & $\begin{array}{c}\text { Heat } \\
\text { advection }\end{array}$ & $\begin{array}{c}\text { Ice } \\
\text { density }\end{array}$ & Cryosuction & $\begin{array}{c}\text { Heat } \\
\text { advection }\end{array}$ & $\begin{array}{c}\text { Ice } \\
\text { density }\end{array}$ & Cryosuction & $\begin{array}{c}\text { Heat } \\
\text { advection }\end{array}$ & $\begin{array}{c}\text { Ice } \\
\text { density }\end{array}$ & Cryosuction \\
\hline Evaporation & 0.9971 & 0.9942 & 0.8991 & 0.9926 & 0.9917 & 0.9365 & 0.9989 & 0.9958 & 0.9033 \\
\hline Discharge & 0.9235 & 0.6282 & 0.8615 & 0.9962 & 0.9377 & 0.6305 & 0.9854 & 0.9874 & 0.6175 \\
\hline Thaw depth & 0.9970 & 0.9961 & 0.8517 & 0.9910 & 0.9791 & 0.9036 & 0.9969 & 0.9887 & 0.9524 \\
\hline 5cm-depth $s_{\mathrm{w}}$ & 0.9959 & 0.9335 & 0.7851 & 0.9916 & 0.7260 & 0.9260 & 0.9979 & 0.5618 & 0.8690 \\
\hline 40cm-depth $s_{\mathrm{w}}$ & 0.9932 & 0.0221 & 0.2130 & 0.9951 & 0.0622 & 0.3111 & 0.9990 & 0.2807 & 0.8498 \\
\hline Surface $T$ & 0.9999 & 0.9999 & 0.9871 & 0.9993 & 0.9990 & 0.8642 & 0.9999 & 0.9996 & 0.9554 \\
\hline $1 \mathrm{~m}$-depth $T$ & 0.9999 & 0.9999 & 0.9207 & 0.9997 & 0.9996 & 0.6127 & 0.9997 & 0.9991 & 0.7366 \\
\hline
\end{tabular}


536 Furthermore, to compare across the physics quantitively, we calculated the mean absolute error

537 (MAE) for each variable of interest over the simulation period of 2011-2020. For evaporation,

538 discharge, and thaw depth, the MAEs are normalized by the corresponding variable average

539 (numbers in Figure 13 (a)); for water saturation and temperature, the MAEs are normalized by

540 their average annual fluctuation range (numbers in Figure 13 (b)). All normalized MAEs are

541 presented in percentage, displayed in Figure 13 according to column- and hillslope-scale (e.g.,

542 south-facing convergent hillslope) models under three different climate conditions. Hillslope-scale

543 model output under conditions of Barrow is not shown in that flat land occupies a majority of the

544 area. A larger normalized MAE percentage indicates greater impact on the variable resulted from

545 a physical process.

546 From the perspective of 10-year average, in general, each physical process of Arctic system

547 discussed in this paper presents a similar impact on variables between column and hillslope scales.

548 Under climate and soil conditions of three different sites, neglecting cryosuction in permafrost

549 modeling leads to the greatest influence on hydrological prediction amongst the three physical

550 assumptions. As seen in Figure 13 (a), it will result in 10\% 20\% deviation in evaporation, 50\%

$551 \sim 60 \%$ in discharge, and $10 \% \sim 30 \%$ in thaw depth. Evaporation is the least affected among the

552 three variables. Discharge is more affected in regions with abundant rainfall (Teller), while in

553 regions with less precipitation, evaporation and thaw depth are relatively affected (Barrow). By

554 comparison, assuming equal ice-liquid density and neglecting advective heat transport may only

555 cause $10 \%$ and $5 \%$ or even much lower error, respectively, in reference to the annual average of a

556 variable. Specially in Barrow, models utilizing the same ice and liquid densities and ignoring

557 advective heat seem to make an obvious impact on discharge, whereas this also results from its

558 extremely low discharge (Figure 7 (b)).

559 Figure 13 (b) illustrates the normalized MAEs of water saturation at $5 \mathrm{~cm}$ beneath surface, as well

560 as temperature at surface and $1 \mathrm{~m}$ depth. The assumption of equal ice-liquid density primarily

561 affects the estimation of water saturation profile. It can lead to about $5 \% \sim 15 \%$ error relative to

562 the annual change range, and the error percentage tends to slightly decrease when applying

563 hillslope-scale models due to the inclusion of lateral flow. Apart from this, neglecting soil

564 cryosuction still makes the largest impact. Surface temperature is the least affected variable among

565 all these model outputs even if cryosuction is not included in modeling. However, at $1 \mathrm{~m}$ depth, 
https://doi.org/10.5194/tc-2021-362

Preprint. Discussion started: 4 January 2022

(c) Author(s) 2022. CC BY 4.0 License.

566 error can increase to $10 \% \sim 30 \%$ by simulation without cryosuction representation.
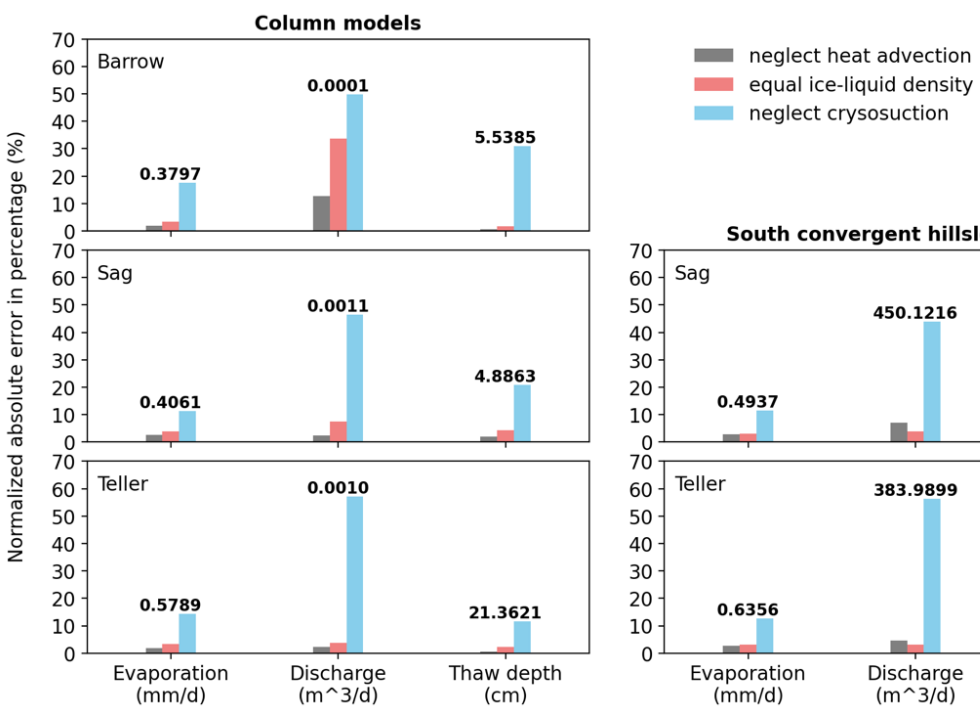

(a) Variables to compare, normalized by variable average
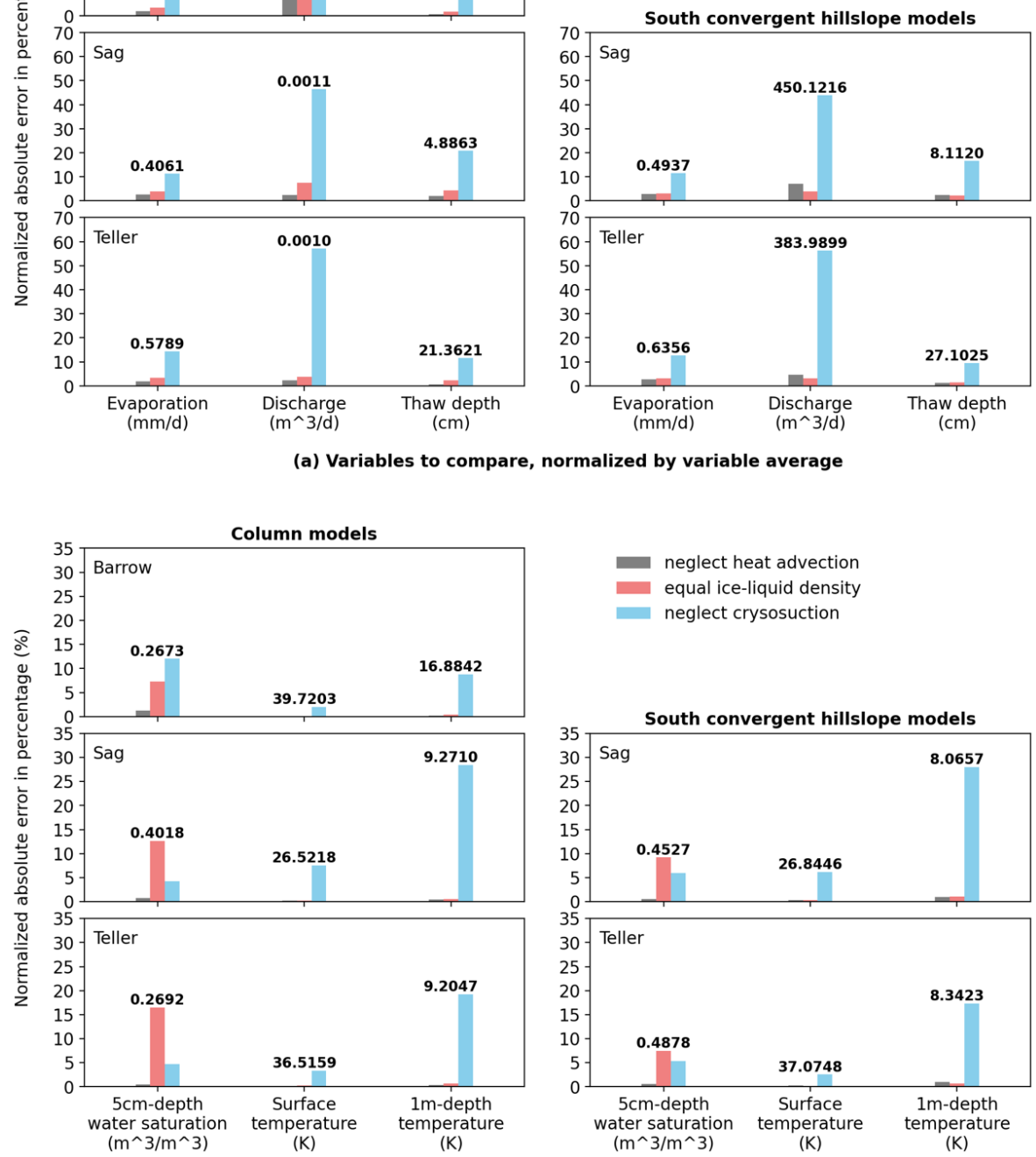

(b) Variables to compare, normalized by average annual fluctuation of variables

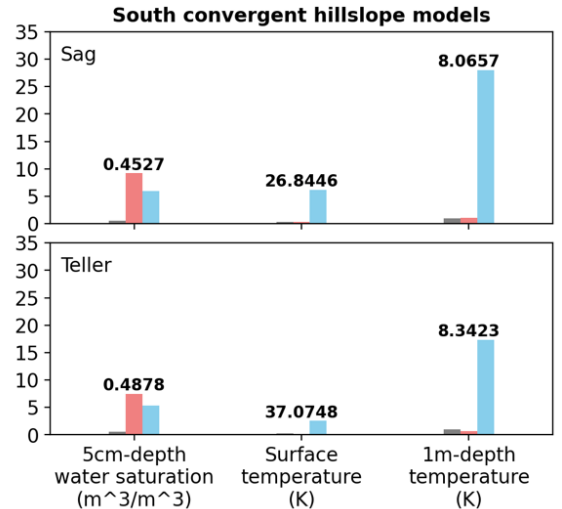

Figure 13 Normalized average absolute error of variables over the period of 2011-2020, compared among three physical assumptions at column and hillslope scales. Variables: (a) evaporation, discharge, and thaw depth, numbers in figures are the average values of the corresponding variables; (b) water saturation, and temperature, numbers in figures are the average annual fluctuation range of each variable.

\section{Conclusion}


575 Simplification of Arctic process representation is an essential consideration when developing 576 process-rich models for thermal permafrost hydrology. There are three subsurface processes that 577 are commonly described in a simplified approach for many Arctic tundra models: (i) ice is 578 prescribed the same density as liquid water; (ii) the effect of soil cryosuction is neglected; (iii) 579 advective heat transport is neglected. Here we investigated the influence of these simplified representations on modeling field-scale permafrost hydrology.

581 To do this, we conducted an ensemble of simulations using the Advanced Terrestrial Simulator 582 (ATS v1.2) to evaluate the impact of the above three process simplifications on field-scale predictions. The ensemble of simulations consisted of 62 numerical experiments considering various conditions, including different climate conditions and soil properties at three sites of Alaska, and different model scale conceptualizations. For evaluation, we compared integrated variables (evaporation, discharge), averaged thaw depth, and pointwise variables (temperature, total water saturation), among different models to access the deviation of applying a simplified modeling assumption. The main conclusions of this study are summarized as follows:

1) Excluding soil cryosuction in permafrost models can cause significant bias in most hydrological variables. Especially, according to this study, the average deviation in evaporation, discharge, and thaw depth may reach $10 \% \sim 20 \%, 50 \% \sim 60 \%$, and $10 \% \sim$ $30 \%$, respectively, relative to the corresponding annual average values. The prediction error for discharge may grow if rainfall rates increase. In the case of pointwise variables, the error in temperature increases from a small amount at the surface up to $10 \% \sim 30 \%$ at $1 \mathrm{~m}$ beneath surface. The prediction of subsurface temperature and water saturation is especially affected when considering hillslope scale models. Therefore, soil cryosuction should be included when modeling permafrost change.

2) Assuming equal ice-liquid density will not result in especially large deviations when predicting most of the hydrological variables, particularly at hillslope scales. It primarily affects the prediction of soil water saturation profile and can cause $5 \% \sim 15 \%$ error relative to the annual saturation fluctuation range. This difference may have consequences for the carbon cycle with regards to the production of methane versus carbon dioxide. Assigning liquid water density for ice may reduce computational time to a small extent in ATS, dependent on simulating conditions and spatial and temporal scales.

3) For a general Arctic tundra system, the prediction error in most variables after neglecting 

advective heat transport is less than 5\%, or even much lower. In the case of ATS, the simulation time cost for hillslope-scale models can decrease by $40 \%$ to $80 \%$ under conditions in this study. Ignoring heat advection in the absence of local, flow-focusing mechanisms, such as thermo-erosion gullies, seems a reasonable decision.

610 Through the comparison of permafrost hydrological outputs obtained from ensemble model setup

611 targeted at field scale, we confirm the importance and necessity of including soil cryosuction effect

612 in predicting permafrost changes, and valid application of equal ice-liquid density and neglecting

613 advective heat transport for a general Arctic system. The latter two may also ease computational

614 cost dependent upon simulation conditions. We expect that this study can contribute to the

615 development of permafrost hydrology models, as well as better selection of physical process

616 representations for modelers.

\section{Code availability}

618 Advanced Terrestrial Simulator (ATS) is an open-source code for solving ecosystem-based, 619 integrated, distributed hydrology, and available at https://github.com/amanzi/ats. Simulations were 620 conducted using version 1.2 (Coon et al., 2021).

622 Data sources of wind speed are cited in the text. The raw forcing data acquired from Daymet, the 623 processed forcing data used for simulation, and simulation output data are available through 624 https://github.com/gaobhub/data_for_paper_model_comparison.

\section{Author contributions}

626 Bo Gao did some revision of the code to add options for process representations, designed 627 numerical experiments and setup models, did data analysis and interpretation, drafted and revised 628 the article. Ethan T. Coon implemented the code in which the study was done, conceptualized the 629 study, helped debug the runs, and helped draft and revise the article.

\section{Competing interests}

631 The authors declare that they have no conflict of interest. 
632

\section{Acknowledgement}

Both authors are supported by the U.S. Department of Energy, Office of Science, Biological and Environmental Research program under the InteRFACE project. This research used resources of the Compute and Data Environment for Science (CADES) at the Oak Ridge National Laboratory, which is supported by the Office of Science of the U.S. Department of Energy under Contract No. DE-AC05-00OR22725.

\section{References}

Abolt, C. J., Young, M. H., Atchley, A. L., Harp, D. R., and Coon, E. T.: Feedbacks Between Surface Deformation and Permafrost Degradation in Ice Wedge Polygons, Arctic Coastal Plain, Alaska, J. Geophys. Res. Earth Surf., 125, e2019JF005349, https://doi.org/10.1029/2019JF005349, 2020.

Atchley, A. L., Painter, S. L., Harp, D. R., Coon, E. T., Wilson, C. J., Liljedahl, A. K., and Romanovsky, V. E.: Using field observations to inform thermal hydrology models of permafrost dynamics with ATS (v0.83), Geosci. Model Dev., 8, 2701-2722, https://doi.org/10.5194/gmd-82701-2015, 2015.

Berteaux, D., Gauthier, G., Domine, F., Ims, R. A., Lamoureux, S. F., Lévesque, E., and Yoccoz, N.: Effects of changing permafrost and snow conditions on tundra wildlife: critical places and times, Arct. Sci., 3, 65-90, https://doi.org/10.1139/as-2016-0023, 2017.

Bui, M. T., Lu, J., and Nie, L.: A Review of Hydrological Models Applied in the PermafrostDominated Arctic Region, Geosciences, 10, 401, https://doi.org/10.3390/geosciences10100401, 2020.

Busey, B., Bolton, B., Wilson, C., and Cohen, L.: Surface Meteorology at Teller Site Stations, Seward Peninsula, Alaska, Ongoing from 2016, Next Generation Ecosystem Experiments Arctic Data Collection, Oak Ridge National Laboratory, U.S. Department of Energy, Oak Ridge, Tennessee, USA. Dataset accessed on October 10, 2021 at https://doi.org/10.5440/1437633, 2017.

Chen, L., Fortier, D., McKenzie, J. M., and Sliger, M.: Impact of heat advection on the thermal regime of roads built on permafrost, Hydrol. Process., 34, 1647-1664, https://doi.org/10.1002/hyp.13688, 2020.

Cheng, G. and $\mathrm{Wu}, \mathrm{T}$.: Responses of permafrost to climate change and their environmental significance, Qinghai-Tibet Plateau, J. Geophys. Res. Earth Surf., 112, https://doi.org/10.1029/2006JF000631, 2007.

Coon, E. T., David Moulton, J., and Painter, S. L.: Managing complexity in simulations of land surface and near-surface processes, Environ. Model. Softw., 78, 134-149, https://doi.org/10.1016/j.envsoft.2015.12.017, 2016.

Coon, E. T., Moulton, J. D., Kikinzon, E., Berndt, M., Manzini, G., Garimella, R., Lipnikov, K., and Painter, S. L.: Coupling surface flow and subsurface flow in complex soil structures using 
669 mimetic finite differences, Adv. Water Resour., 144, 103701,

670 https://doi.org/10.1016/j.advwatres.2020.103701, 2020.

671 Coon, E. T., Berndt, M., Jan, A., Svyatsky, D., Atchley, A. L., Kikinzon, E., Harp, D. R., 672 Manzini, G., Shelef, E., Lipnikov, K., Garimella, R., Xu, C., Moulton, D., Karra, S., Painter, S.

673 L., Jafarov, E., and Molins, S.: Advanced Terrestrial Simulator. U.S. Department of Energy,

674 USA. Version 1.2. DOI: 10.11578/dc.20190911.1, 2021.

675 Dall'Amico, M., Endrizzi, S., Gruber, S., and Rigon, R.: A robust and energy-conserving model

676 of freezing variably-saturated soil, The Cryosphere, 5, 469-484, https://doi.org/10.5194/tc-5-

677 469-2011, 2011.

678 Dearborn, K. D., Wallace, C. A., Patankar, R., and Baltzer, J. L.: Permafrost thaw in boreal

679 peatlands is rapidly altering forest community composition, J. Ecol., 109, 1452-1467,

680 https://doi.org/10.1111/1365-2745.13569, 2021.

681 Devoie, É. G. and Craig, J. R.: A Semianalytical Interface Model of Soil Freeze/Thaw and

682 Permafrost Evolution, Water Resour. Res., 56, e2020WR027638,

683 https://doi.org/10.1029/2020WR027638, 2020.

684 Endrizzi, S., Gruber, S., Dall'Amico, M., and Rigon, R.: GEOtop 2.0: simulating the combined

685

686

687

688

689

690

691

692

693

694

695

696

697

698

699

700

701

702

703

704

705

706

707

708

709 energy and water balance at and below the land surface accounting for soil freezing, snow cover and terrain effects, Geosci. Model Dev., 7, 2831-2857, https://doi.org/10.5194/gmd-7-28312014, 2014.

Fortier, D., Allard, M., and Shur, Y.: Observation of rapid drainage system development by thermal erosion of ice wedges on Bylot Island, Canadian Arctic Archipelago, Permafr. Periglac. Process., 18, 229-243, https://doi.org/10.1002/ppp.595, 2007.

Godin, E., Fortier, D., and Coulombe, S.: Effects of thermo-erosion gullying on hydrologic flow networks, discharge and soil loss, Environ. Res. Lett., 9, 105010, https://doi.org/10.1088/17489326/9/10/105010, 2014.

Gottardi, G. and Venutelli, M.: A control-volume finite-element model for two-dimensional overland flow, Adv. Water Resour., 16, 277-284, https://doi.org/10.1016/0309-1708(93)90019C, 1993.

Harp, D. R., Zlotnik, V., Abolt, C. J., Busey, B., Avendaño, S. T., Newman, B. D., Atchley, A. L., Jafarov, E., Wilson, C. J., and Bennett, K. E.: New insights into the drainage of inundated ice-wedge polygons using fundamental hydrologic principles, The Cryosphere, 15, 4005-4029, https://doi.org/10.5194/tc-15-4005-2021, 2021.

Hinzman, L., Busey, B., Cable, W., and Romanovsky, V.: Surface Meteorology, Utqiagvik (Barrow), Alaska, Area A, B, C and D, Ongoing from 2012, Next Generation Ecosystem Experiments Arctic Data Collection, Oak Ridge National Laboratory, U.S. Department of Energy, Oak Ridge, Tennessee, USA. Dataset accessed on October 10, 2021 at https://doi.org/10.5440/1164893, 2014.

Hjort, J., Karjalainen, O., Aalto, J., Westermann, S., Romanovsky, V. E., Nelson, F. E., Etzelmüller, B., and Luoto, M.: Degrading permafrost puts Arctic infrastructure at risk by midcentury, Nat. Commun., 9, 5147, https://doi.org/10.1038/s41467-018-07557-4, 2018.

Hugelius, G., Strauss, J., Zubrzycki, S., Harden, J. W., Schuur, E. a. G., Ping, C.-L., 
710 Schirrmeister, L., Grosse, G., Michaelson, G. J., Koven, C. D., O’Donnell, J. A., Elberling, B., 711 Mishra, U., Camill, P., Yu, Z., Palmtag, J., and Kuhry, P.: Estimated stocks of circumpolar 712 permafrost carbon with quantified uncertainty ranges and identified data gaps, Biogeosciences, 713 11, 6573-6593, https://doi.org/10.5194/bg-11-6573-2014, 2014.

714 Jafarov, E. E., Coon, E. T., Harp, D. R., Wilson, C. J., Painter, S. L., Atchley, A. L., and 715 Romanovsky, V. E.: Modeling the role of preferential snow accumulation in through talik development and hillslope groundwater flow in a transitional permafrost landscape, Environ. Res. Lett., 13, 105006, https://doi.org/10.1088/1748-9326/aadd30, 2018. Jan, A., Coon, E. T., Painter, S. L., Garimella, R., and Moulton, J. D.: An intermediate-scale model for thermal hydrology in low-relief permafrost-affected landscapes, Comput. Geosci., 22, 163-177, https://doi.org/10.1007/s10596-017-9679-3, 2018.

Jan, A., Coon, E. T., and Painter, S. L.: Evaluating integrated surface/subsurface permafrost thermal hydrology models in ATS (v0.88) against observations from a polygonal tundra site, Geosci. Model Dev., 13, 2259-2276, https://doi.org/10.5194/gmd-13-2259-2020, 2020.

Jorgenson, M. T., Racine, C. H., Walters, J. C., and Osterkamp, T. E.: Permafrost Degradation and Ecological Changes Associated with a WarmingClimate in Central Alaska, Clim. Change, 48, 551-579, https://doi.org/10.1023/A:1005667424292, 2001.

Karra, S., Painter, S. L., and Lichtner, P. C.: Three-phase numerical model for subsurface hydrology in permafrost-affected regions (PFLOTRAN-ICE v1.0), The Cryosphere, 8, 19351950, https://doi.org/10.5194/tc-8-1935-2014, 2014.

Kurylyk, B. L. and Watanabe, K.: The mathematical representation of freezing and thawing processes in variably-saturated, non-deformable soils, Adv. Water Resour., 60, 160-177, https://doi.org/10.1016/j.advwatres.2013.07.016, 2013.

Kurylyk, B. L., MacQuarrie, K. T. B., and McKenzie, J. M.: Climate change impacts on groundwater and soil temperatures in cold and temperate regions: Implications, mathematical theory, and emerging simulation tools, Earth-Sci. Rev., 138, 313-334, https://doi.org/10.1016/j.earscirev.2014.06.006, 2014.

Luethi, R., Phillips, M., and Lehning, M.: Estimating Non-Conductive Heat Flow Leading to Intra-Permafrost Talik Formation at the Ritigraben Rock Glacier (Western Swiss Alps), Permafr. Periglac. Process., 28, 183-194, https://doi.org/10.1002/ppp.1911, 2017.

McKenzie, J. M. and Voss, C. I.: Permafrost thaw in a nested groundwater-flow system, Hydrogeol. J., 21, 299-316, https://doi.org/10.1007/s10040-012-0942-3, 2013.

McKenzie, J. M., Voss, C. I., and Siegel, D. I.: Groundwater flow with energy transport and water-ice phase change: numerical simulations, benchmarks, and application to freezing in peat bogs, Adv. Water Resour., 30, 966-983, https://doi.org/10.1016/j.advwatres.2006.08.008, 2007.

NEON (National Ecological Observatory Network): 2D wind speed and direction (DP1.00001.001): RELEASE-2021, https://doi.org/10.48443/s9ya-zc81, 2021. Dataset accessed from https://data.neonscience.org on October 10, 2021.

Nixon, J. F.: The Role of Convective Heat Transport in the Thawing of Frozen Soils, Can. Geotech. J., 12, 425-429, https://doi.org/10.1139/t75-046, 1975.

Noh, J.-H., Lee, S.-R., and Park, H.: Prediction of cryo-SWCC during freezing based on pore- 
size distribution, Int. J. Geomech., 12, 428-438, https://doi.org/10.1061/(ASCE)GM.19435622.0000134, 2012.

O'Connor, M. T., Cardenas, M. B., Ferencz, S. B., Wu, Y., Neilson, B. T., Chen, J., and Kling, G. W.: Empirical Models for Predicting Water and Heat Flow Properties of Permafrost Soils, Geophys. Res. Lett., 47, e2020GL087646, https://doi.org/10.1029/2020GL087646, 2020.

Painter, S. L.: Three-phase numerical model of water migration in partially frozen geological media: model formulation, validation, and applications, Comput. Geosci., 15, 69-85, https://doi.org/10.1007/s10596-010-9197-z, 2011.

Painter, S. L. and Karra, S.: Constitutive Model for Unfrozen Water Content in Subfreezing Unsaturated Soils, Vadose Zone J., 13, vzj2013.04.0071, https://doi.org/10.2136/vzj2013.04.0071, 2014.

Painter, S. L., Coon, E. T., Atchley, A. L., Berndt, M., Garimella, R., Moulton, J. D., Svyatskiy, D., and Wilson, C. J.: Integrated surface/subsurface permafrost thermal hydrology: Model formulation and proof-of-concept simulations: integrated pemafrost thermal hydrology, Water Resour. Res., 52, 6062-6077, https://doi.org/10.1002/2015WR018427, 2016.

Riseborough, D., Shiklomanov, N., Etzelmüller, B., Gruber, S., and Marchenko, S.: Recent advances in permafrost modelling, Permafr. Periglac. Process., 19, 137-156, https://doi.org/10.1002/ppp.615, 2008.

Rowland, J. C., Travis, B. J., and Wilson, C. J.: The role of advective heat transport in talik development beneath lakes and ponds in discontinuous permafrost, Geophys. Res. Lett., 38, https://doi.org/10.1029/2011GL048497, 2011.

Sjöberg, Y., Coon, E., K. Sannel, A. B., Pannetier, R., Harp, D., Frampton, A., Painter, S. L., and Lyon, S. W.: Thermal effects of groundwater flow through subarctic fens: A case study based on field observations and numerical modeling, Water Resour. Res., 52, 1591-1606, https://doi.org/10.1002/2015WR017571, 2016.

Stuurop, J. C., van der Zee, S. E. A. T. M., Voss, C. I., and French, H. K.: Simulating water and heat transport with freezing and cryosuction in unsaturated soil: Comparing an empirical, semiempirical and physically-based approach, Adv. Water Resour., 149, 103846, https://doi.org/10.1016/j.advwatres.2021.103846, 2021.

Sugimoto, A., Yanagisawa, N., Naito, D., Fujita, N., and Maximov, T. C.: Importance of permafrost as a source of water for plants in east Siberian taiga, Ecol. Res., 17, 493-503, https://doi.org/10.1046/j.1440-1703.2002.00506.x, 2002.

Tesi, T., Muschitiello, F., Smittenberg, R. H., Jakobsson, M., Vonk, J. E., Hill, P., Andersson, A., Kirchner, N., Noormets, R., Dudarev, O., Semiletov, I., and Gustafsson, Ö.: Massive remobilization of permafrost carbon during post-glacial warming, Nat. Commun., 7, 13653, https://doi.org/10.1038/ncomms13653, 2016.

Thornton, M. M., Wei, Y., Thornton, P. E., Shrestha, R., Kao, S., and Wilson, B. E.: Daymet: Station-Level Inputs and Cross-Validation Result for North America, Version 4, https://doi.org/10.3334/ORNLDAAC/1850, 2020.

Thornton, P. E., Shrestha, R., Thornton, M., Kao, S.-C., Wei, Y., and Wilson, B. E.: Gridded daily weather data for North America with comprehensive uncertainty quantification, Sci. Data, 
793 Van Genuchten, M. T.: A Closed-form Equation for Predicting the Hydraulic Conductivity of

794 Unsaturated Soils, Soil Sci. Soc. Am. J., 44, 892-898,

795 https://doi.org/10.2136/sssaj1980.03615995004400050002x, 1980.

796 Viterbo, P., Beljaars, A., Mahfouf, J.-F., and Teixeira, J.: The representation of soil moisture

797 freezing and its impact on the stable boundary layer, Q. J. R. Meteorol. Soc., 125, 2401-2426,

798 https://doi.org/10.1002/qj.49712555904, 1999.

799 Walvoord, M. A. and Kurylyk, B. L.: Hydrologic Impacts of Thawing Permafrost-A Review, 800 Vadose Zone J., 15, https://doi.org/10.2136/vzj2016.01.0010, 2016.

801 Wasantha Lal, A. M.: Weighted Implicit Finite-Volume Model for Overland Flow, J. Hydraul. 802 Eng., 124, 941-950, https://doi.org/10.1061/(ASCE)0733-9429(1998)124:9(941), 1998.

803 Weismüller, J., Wollschläger, U., Boike, J., Pan, X., Yu, Q., and Roth, K.: Modeling the thermal 804 dynamics of the active layer at two contrasting permafrost sites on Svalbard and on the Tibetan 805 Plateau, The Cryosphere, 5, 741-757, https://doi.org/10.5194/tc-5-741-2011, 2011.

806 Westermann, S., Langer, M., Boike, J., Heikenfeld, M., Peter, M., Etzelmüller, B., and Krinner, 807 G.: Simulating the thermal regime and thaw processes of ice-rich permafrost ground with the 808 land-surface model CryoGrid 3, Geosci. Model Dev., 9, 523-546, https://doi.org/10.5194/gmd-9809 523-2016, 2016.

810 Zhang, T., Barry, R. G., Knowles, K., Heginbottom, J. A., and Brown, J.: Statistics and 811 characteristics of permafrost and ground-ice distribution in the Northern Hemisphere, Polar 812 Geogr., 31, 47-68, https://doi.org/10.1080/10889370802175895, 2008. 